\title{
Sleep apnoea as an independent risk factor for cardiovascular disease: current evidence, basic mechanisms and research priorities
}

\author{
W.T. McNicholas*, M.R. Bonsignore ${ }^{\#}$ and the Management Committee of EU COST \\ ACTION B26
}

ABSTRACT: Considerable evidence is available in support of an independent association between obstructive sleep apnoea syndrome (OSAS) and cardiovascular disease, which is particularly strong for systemic arterial hypertension and growing for ischaemic heart disease, stroke, heart failure, atrial fibrillation and cardiac sudden death.

The pathogenesis of cardiovascular disease in OSAS is not completely understood but likely to be multifactorial, involving a diverse range of mechanisms including sympathetic nervous system overactivity, selective activation of inflammatory molecular pathways, endothelial dysfunction, abnormal coagulation and metabolic dysregulation, the latter particularly involving insulin resistance and disordered lipid metabolism.

The present report, which arose out of a European Union Cooperation in the field of Scientific and Technical Research (COST) action on OSAS (COST B26), reviews the current evidence for an independent association and proposes research priorities to identify the underlying mechanisms involved, with a view to identifying novel therapeutic strategies.

Large-scale collaborative studies of carefully defined patient populations with obstructive sleep apnoea syndrome, adequately controlled for potential confounders, are needed. Such studies carry the prospect of evaluating potential interactions between different basic mechanisms operating in obstructive sleep apnoea syndrome and cardiovascular disease, and interactions with other related disorders, such as obesity, diabetes and dyslipidaemia. Furthermore, translational studies involving cell culture and animal models linked to studies of obstructive sleep apnoea syndrome patients are necessary to integrate basic mechanisms with the clinical disorder.

KEYWORDS: Cardiovascular disease, intermittent hypoxia, mechanisms, obstructive sleep apnoea

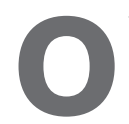

bstructive sleep apnoea syndrome (OSAS) is characterised by repeated episodes of upper airway obstruction during sleep, associated with increasing respiratory efforts, intermittent arterial oxygen desaturation, systemic and pulmonary arterial blood pressure surges and sleep disruption. The main symptoms of OSAS are nocturnal respiratory pauses interrupted by loud intermittent snoring and excessive daytime somnolence. According to the recently updated International Classification of Sleep Disorders published by the American Academy of Sleep Medicine, a diagnosis of OSAS can be made if the respiratory disturbance index
(RDI) is $\geqslant 15$, independent of occurrence of symptoms, or whenever an RDI $>5$ is associated with any of the following: 1) sleep attacks, excessive daytime sleepiness (EDS), unrefreshing sleep, fatigue or insomnia; 2) awakenings with a choking sensation; or 3) witnessed heavy snoring and/or breathing pauses referred by the partner [1]. The definitions of sleep-related respiratory disturbances have been clarified in recent years, particularly apnoea, hypopnoea and respiratory effort-related arousals [1-3]. The gold standard technique for the diagnosis of sleep apnoea and related disorders is overnight polysomnography, although increasing attention is being paid to the

\section{AFFILIATIONS}

*Respiratory Sleep Disorders Unit, St Vincent's University Hospital, Dublin, Ireland.

"Dept of Medicine, Pneumology, Physiology and Nutrition (DIMPEFINU), University of Palermo, Palermo, Italy.

\section{CORRESPONDENCE}

W.T. McNicholas

Respiratory Sleep Disorders Unit

St. Vincent's University Hospital

Elm Park

Dublin 4

Ireland

Fax: 35312697949

E-mail: walter.mcnicholas@ucd.ie

Received:

February 232006

Accepted after revision:

August 282006 
development of limited diagnostic systems for use in clinical practice, which assess cardiorespiratory variables during overnight studies. These latter systems require a lower level of logistical support than polysomnography and many are suitable for home-based sleep studies.

Current knowledge on the natural history of the disease is still limited [4], but the long-term consequences of OSAS appear relevant. Untreated OSAS increases the risk for car accidents [5], and worsens quality of life [6] and mood [7, 8]. The major health risk in OSAS patients, however, is the strong association with acute cardiovascular events (i.e. stroke, myocardial infarction and nocturnal sudden death) and chronic conditions such as systemic hypertension, coronary artery disease and heart failure [9].

OSAS can be effectively treated by applying nasal continuous positive airway pressure (CPAP) during sleep [10-12]. However, although CPAP technology has improved considerably over the years, acceptance of CPAP therapy remains a problem in patients without excessive daytime somnolence. Other options are available such as oral appliances [13] and upper airway surgery [14] but their use is not firmly evidence based as prospective randomised trials on current therapeutic and preventive efficacy are still lacking [13-15]. Therefore, the choice of therapy and the impact of preventive strategies on the long-term health effects of OSAS remain open questions. From a public health perspective, epidemiological and clinical studies on OSAS are cost-effective investments, since CPAP treatment decreases the excess healthcare costs for cardiovascular disease [16-18] and car accidents [19, 20] incurred by OSAS patients before diagnosis. Moreover, the cost effectiveness of early OSAS management increases with OSAS severity [21].

OSAS is a highly prevalent disease in the population, affecting $\geqslant 4 \%$ of males and $2 \%$ of females [22]. Population studies have shown that both sleep apnoea and daytime somnolence are frequent in the general population and increase with age [23, $24]$. The typical OSAS patient is male, middle-aged and obese. Obesity unfavourably affects respiratory function and may promote the collapse of upper airways during sleep [25]; in addition, when body weight increases, the frequency of respiratory events during sleep also rises [26]. In the USA, the current epidemic of obesity has been estimated to account for up to $40 \%$ of cases of sleep-disordered breathing (SDB) in adults [27]; whether such figures might also be applicable in non-USA populations is unclear. For example, the correlation between obesity and the apnoea/hypopnoea index (AHI) is weaker in Asian than in Caucasian subjects, suggesting that racial factors may affect OSAS prevalence through craniofacial structure [28, 29]. In Europe, the prevalence of obesity is lower than in the USA, with a higher proportion of relatively lean OSAS patients referred to sleep clinics. In summary, while the association of OSAS and obesity is unquestionable, the pathophysiology and health consequences of mild-to-severe OSAS in nonobese patients are still incompletely defined.

Besides decreasing lung function, obesity increases cardiovascular risk, making it hard to assess the independent role of OSAS on cardiovascular morbidity and mortality. The interrelationships between obesity and OSAS are complex and possibly bidirectional [30], and some authors believe that OSAS should be considered as one manifestation of the metabolic syndrome (i.e. a cluster of cardiovascular risk factors) rather than a "local" disease principally affecting the upper airways [31].

From a clinical viewpoint, a pragmatic approach to treating OSAS and preventing cardiovascular events would be desirable. Even if OSAS exerted no independent effect on the prevalence or severity of cardiovascular disease, the cluster of risk factors in OSAS patients is often so impressive that it would warrant active intervention, even without knowing the precise relative role played by each factor. In other words, given the frequent association of OSAS and other major risk factors, the best approach could be to aggressively address not only respiratory disturbances during sleep but also the metabolic, inflammatory and cardiovascular problems of OSAS patients. This would require a highly organised and motivated effort, by both medical and social institutions.

European research has contributed to pivotal, top-quality research on SDB since the 1960s, but current clinical and basic research investments on OSAS in the European Union (EU) are very disappointing. The impact of low institutional funding is worsened by scarce investments by the pharmaceutical industry, since OSA treatment is not "pill based". In addition, the multidisciplinary nature of the disease probably contributes to dispersion of funding among different medical specialties (neurology, respiratory medicine, cardiology, endocrinology and obesity centres, otolaryngology and dentistry) without efficient coordination at the European level. Conversely, in North America, at least four large population studies (Wisconsin Sleep Cohort, Sleep Heart Health Study, Pennsylvania Sleep Cohort and Cleveland Family Study) have provided cross-sectional and longitudinal data to assess the natural history of OSAS and collect long-term results on cardiovascular morbidity and mortality [22,32-36]. Differences in lifestyle and prevalence of obesity between Europe and North America [37] highlight the necessity to develop research programmes specifically focused on the European population.

Unfortunately, the current status of European research on OSAS reveals the same problems recently highlighted for diabetes, another major disease for which European research is not sufficiently supported, despite the high social and health costs. The problems for diabetes are that funding resources are insufficient, effective central coordination is lacking, and the efficiency of investments in Europe is poor compared with the USA [38]. A European initiative for diabetes (EURADIA) has been jointly developed by scientific societies and the pharmaceutical industry to increase the chances of reversing the European lack of competitiveness in this research area.

A similar joint effort of the European Scientific Community dealing with sleep medicine resulted in the proposal of an Action on OSAS through the EU Cooperation in Scientific and Technological research (COST) programme. The most important feature of the COST programme is the "bottom-up" approach, which reflects demands directly raised by the scientific community and helps create and strengthen scientific relationships and disseminate information on the Internet [39]. The Action B26 on OSAS was approved in March 2005 and 
started on May 31, 2005 [40]. The first objective, jointly developed with the European Respiratory Society, has been to review the current state of the art in order to indicate strategically relevant directions for OSAS research in Europe. Additional connections have been established or are planned with other scientific societies focusing on sleep, cardiovascular disease and hypertension to foster multidisciplinary discussion on OSAS research and aim at providing effective prevention and treatment of OSAS and its consequences.

The programme of the COST B26 Action is to promote the integration of European research on OSAS to better understand: 1) the genetic and cell biological mechanisms by which intermittent hypoxia is detrimental for cardiovascular health; and 2) the mechanisms responsible for highly variable levels of EDS in OSAS patients. In addition, the Action will address genetic and epidemiological issues applied to the European population as useful steps to better identify patients at particularly high cardiovascular risk, and to develop further alternatives to CPAP therapy.

The current review discusses: 1) the epidemiologic and clinical evidence of OSAS associated cardiovascular involvement; and 2) the current evidence on pathogenetic mechanisms that affect subjects with untreated OSAS, in order to identify "hot" topics and propose priorities for future research.

\section{DOES OSAS INDEPENDENTLY INCREASE CARDIOVASCULAR RISK?}

Early concerns about possible consequences of SDB in patients with severe OSAS focused on the possibility that nocturnal hypoxaemia might cause pulmonary hypertension and cor pulmonale. However, pulmonary arterial pressure is only modestly elevated during sleep and wakefulness in subjects with uncomplicated OSAS [41]. Rather, the systemic circulation was soon recognised as a major target of OSAS. As early as 1980, the San Marino epidemiological study by LUGARESI et al. [42] highlighted the association of systemic hypertension and snoring in the general population. Ten years later, a high prevalence of cardiovascular disease (systemic hypertension, coronary artery disease and cerebrovascular disease) in OSAS patients at diagnosis, and a dose-response effect between cardiovascular involvement and OSAS severity, was reported by the Stanford group [43].

Nowadays, evidence for an association of OSAS with several aspects of cardiovascular disease and/or risk is available. The literature on the different aspects of this topic is extensive, and a full discussion of all relevant papers is beyond the scope of the current review. Reference to extensive reviews, which the interested reader is referred to, is provided at the beginning of each of the following sections, while the most recent papers on each topic are reported in detail.

\section{Cardiovascular morbidity and mortality}

According to uncontrolled studies, untreated moderate-tosevere OSAS was associated with increased rates of nonfatal cardiovascular events after a relatively short follow-up [43, 44]. At least four longitudinal studies have confirmed increased cardiovascular morbidity in OSAS patients [45-48], but the concomitant occurrence of other cardiovascular risk factors often limited the assessment of an independent pathogenetic role for OSAS [49]. A prospective 5-yr study analysed cardiovascular outcomes in 400 subjects according to snoring status and the presence of cardiovascular risk factors, and reported a significant increase in the number of fatal and nonfatal cardiovascular events in subjects positive for both snoring and other well-established risk factors present at study entry. Conversely, either simple snorer status or the isolated occurrence of cardiovascular risk factors increased the risk only slightly [45]. In consecutive subjects with suspected OSAS and no clinical evidence of cardiovascular disease, OSAS patients who refused treatment had a higher incidence of cardiovascular events in the 7 yrs following diagnosis compared with non-OSAS subjects and patients compliant with CPAP therapy [46]. Overall, the bulk of available data indicate a high risk for cardiovascular events in untreated OSAS.

However, the association of OSAS and cardiovascular disease does not necessarily imply a cause-effect relationship. OSAS patients are often obese and show evidence of the metabolic syndrome (i.e. at least three of the following cardiovascular risk factors: central obesity, systemic hypertension, low highdensity lipoprotein cholesterol (HDL-C), high triglycerides, and impaired glucose tolerance). Such a clinical context makes it difficult to assess the independent effects of OSAS on cardiovascular risk $[49,50]$.

Two recent studies assessed cardiovascular prognosis in OSAS over 10 yrs after diagnosis [47, 48]. Patients were free to accept or refuse CPAP treatment, but neither study was randomised due to the ethical unacceptability of withholding effective CPAP therapy for such a long time. The study by MARIN et al. [47] showed that long-term cardiovascular morbidity and mortality increased only in patients with untreated severe OSAS, whereas simple snorers, OSAS patients with mild disease or patients with severe OSAS who accepted CPAP treatment showed morbidity and mortality figures very similar to those obtained in the general population. The study by DOHERTY et al. [48] instead, suggested that untreated OSAS may increase the severity rather than the prevalence of cardiovascular disease. Indeed, the incidence of hypertension, ischaemic heart disease and other cardiovascular disorders during follow-up was not significantly different in treated and untreated patients, irrespective of acceptance or refusal of CPAP treatment. However, only untreated patients showed excess cardiovascular mortality during follow-up [48]. Finally, an increased risk for death or stroke and a dose-effect relationship between OSAS severity and risk were reported in a large patient series followed for a median of $3.4 \mathrm{yrs}$. Unfortunately, the short duration of follow-up and the small number of observed events did not allow the specific assessment of the effects of therapy [51].

Data on cardiovascular mortality further indicate the need to effectively treat severe OSAS in order to avoid potentially catastrophic cardiovascular consequences, especially in young patients. The first observational reports on cardiovascular mortality in OSAS $[52,53]$ were confirmed by later studies. Before the introduction of CPAP into clinical practice, patients with mild-to-moderate OSAS who had been conservatively treated and encouraged to lose weight showed a higher 5-8-yr cardiovascular morbidity and mortality compared with patients who had been tracheostomised because of very severe 
OSAS. In the latter group, survival was similar to that of the general population $[52,53]$. The cardiovascular effects of OSAS appear particularly dangerous in young subjects [53], as recently confirmed after long-term follow-up of almost 15,000 patients [54]. The patient cohort analysed by MARIN et al. [47] also showed high mortality rates in the youngest age groups. Conversely, CPAP-treated patients who were compliant with treatment had mortality rates similar to those recorded in the general population [55], whereas excess cardiovascular fatal events occurred in patients aged $<50$ yrs who refused CPAP treatment $[55,56]$. Indeed, the major determinant of long-term outcome was compliance with CPAP treatment rather than severity of OSAS at diagnosis [57].

OSAS may also be involved in the pathogenesis of nocturnal sudden death. In 1991, SEPPÄLÄ et al. [58] reported that increasing snoring severity was associated with increased risk for nocturnal sudden death, but the data were only indicative of a possible association of OSAS and nocturnal events since they were not based on polysomnographic recordings. In patients with polysomnographic diagnosis of OSAS, GAMI et al. [59] found that the risk of nocturnal (between 00:00-06:00 hrs) sudden death increased with OSAS severity, whereas cardiovascular events mostly occurred between 06:00-12:00 hrs in patients with no sleep apnoea or subjects from the general population. The role of CPAP treatment could not be assessed in this study, but the authors proposed that the good compliance with treatment expected in patients with severe OSAS suggests that CPAP probably had little effect on the results. This proposal is at variance with the significant protection reported by CPAP treatment in several other observational studies, and deserves prospective and carefully designed long-term studies before definitive conclusions can be drawn.

\section{Hypertension}

There is strong evidence that OSAS is an independent risk factor for systemic hypertension [9, 60-62]. Careful casecontrol studies have confirmed the association of sleep apnoea and increased blood pressure independent of confounders such as obesity [63]. Also, data in patient and population samples extensively support a role for OSAS in the pathogenesis of hypertension [46, 64-70]. In longitudinal population studies, SDB increased the risk for increased blood pressure at follow-up [71, 72]. Prospective randomised trials have shown that OSAS treatment decreases blood pressure [73, 74], especially in hypertensive subjects [75-77].

The role of intermittent hypoxia in the pathogenesis of systemic hypertension is unclear. A causal relationship between intermittent hypoxia during sleep, systemic hypertension and cardiac hypertrophy has been convincingly demonstrated in a chronic dog model of OSAS [78, 79] and in rats exposed to intermittent hypoxia [80]. However, a recent randomised controlled study in OSAS patients showed decreased blood pressure after effective CPAP treatment, but not after sham-CPAP together with supplemental nocturnal oxygen for 2 weeks [81]. Therefore, while the role of OSAS in increasing blood pressure can be considered proven, the independent role of intermittent hypoxia on blood pressure regulation in humans still awaits confirmation.
Systemic hypertension in OSAS is a major clinical problem, especially as it is greatly underdiagnosed. In one study, the prevalence of hypertension was $67 \%$ in newly diagnosed OSAS patients not known to be hypertensive before undergoing assessment for SDB [82]. Notably, the role of OSAS as a cause of underdiagnosed hypertension has been recently acknowledged [83]. The isolated increase in diastolic blood pressure might be the earliest hypertensive change associated with OSAS [82, 84], whereas isolated systolic hypertension was uncommon in subjects with SDB $[85,86]$. Instead, a high prevalence of systolic hypertension was found in patients with OSAS and chronic heart failure [87]. Most OSAS patients, however, show elevated systolic and diastolic blood pressure values $[85,86]$, as well as increased blood pressure variability during sleep [88] and decreased baroreflex sensitivity [82, 89]. Overall, hypertension, increased blood pressure variability and decreased effectiveness of cardiovascular control mechanisms may all contribute to the increased cardiovascular risk of OSAS.

Assessing the independent pathogenetic role of OSAS in left ventricular hypertrophy is complicated by multifactorial influences potentially affecting cardiac structure, such as hypertension, obesity, intermittent hypoxia and mechanical changes associated with apnoeas [90,91]. There is agreement, however, that patients with moderate-to-severe OSAS show an increased prevalence of left ventricular hypertrophy [82, 90-95] and diastolic dysfunction [96, 97], both being reversed by CPAP treatment.

The relationship between SDB and systemic blood pressure appears variable in paediatric OSA [98-100] and in population studies of snoring children [100, 101]. Children with OSAS showed left ventricular diastolic dysfunction with increasing apnoea severity [102, 103], autonomic dysfunction [104], increased circulating inflammatory markers [105-107] and adhesion molecules [106], suggesting similar potential pathogenetic mechanisms of cardiovascular damage in adult and paediatric SDB. More data are clearly needed to better understand the immediate and long-term cardiovascular impact of sleep apnoea in children [108, 109].

\section{Coronary artery disease}

The association of obstructive sleep apnoeas and coronary artery disease (CAD) has been documented in patient series selected for either disease [110-112] and in a cross-sectional analysis of the Sleep Heart Health Study cohort data [113]. Reviews on the relationship between ischaemic heart disease and sleep apnoea are available [114-116].

Untreated OSAS worsens the prognosis of patients with CAD. In addition to the increased incidence of nocturnal sudden death in patients with OSAS compared with the general population [58,59], patients with known CAD and an RDI $>10$ events $\cdot h^{-1}$ were much more likely to experience cardiovascular death over a 5-yr period than those with low RDI (37.5 versus $9.3 \%$, respectively) after controlling for age, weight and smoking [116]. In longitudinal studies, untreated SDB significantly worsened the prognosis of patients with documented CAD [117], whereas patients with CAD and OSAS receiving CPAP had a better clinical course compared with those who refused treatment [118]. An increased incidence of CAD in patients clinically free of coronary symptoms at the time of 
OSAS diagnosis, and a protective effect of CPAP treatment, have been recently reported by a prospective 7-yr follow-up study in the Gothenburg Sleep Cohort [119]. Moreover, the frequency of nocturnal desaturations correlated with the extent of coronary lesions and explained $13.4 \%$ of their variance, suggesting a pathogenetic role of OSAS in coronary atherosclerosis [120]. Some studies, however, did not confirm that OSAS worsened the prognosis of patients with CAD, as 10-yr survival did not differ between apnoeic and nonapnoeic subjects in a small series of 50 coronary patients [121].

OSAS may precipitate angina or myocardial ischaemia during sleep in patients with coronary lesions [115]. Given the high prevalence of both OSAS and CAD, the frequency of nocturnal anginal symptoms was found to be surprisingly low in OSAS patients [122]. Nocturnal angina occurred in $<1 \%$ of 4,000 patients studied by polysomnography and eight-channel electrocardiogram monitoring [122]. In addition, the symptomatic association of OSAS and CAD has been documented only by case reports or small patient series [115]. In summary, available data in patients with OSAS and nocturnal angina agree that the extent of coronary lesions is variable and angina symptoms are resolved with CPAP treatment [115]. Serum cardiac troponin $\mathrm{T}$, a marker of myocardial damage, did not show evidence of injury in a small series of CAD patients with OSAS at baseline or during acute CPAP application [123]. It is likely that some still unknown additional predisposing factors are necessary for OSAS to trigger significant coronary insufficiency during sleep. Experimental data in rats indicate that daily exposure to intermittent hypoxia (IH) for $8 \mathrm{~h} \cdot \mathrm{day}^{-1}$ for 35 days increased infarct size after ischaemia-reperfusion, in the absence of significant changes in arterial blood pressure in vivo or evidence of vascular/endothelial dysfunction [124]. However, the modality of exposure to IH may significantly affect the myocardial response to ischaemia-reperfusion [125], suggesting that studies at the molecular level are necessary to better understand clinical data obtained in humans.

Asymptomatic electrocardiographic changes may occur during sleep and indicate detrimental effects of obstructive apnoeas on the heart. In a group of 23 OSAS patients without symptoms or history of CAD, about one-third showed asymptomatic STsegment depression during sleep, but only one patient was also positive at the exercise stress test, suggesting a low prevalence of symptomatic coronary artery disease in OSAS [126]. Indeed, isolated apnoea-associated ST-segment changes could be nonspecific (i.e. caused by post-apnoeic hyperventilation). Conversely, up to one-third of OSA patients with angiographically proven coronary lesions showed ST-segment changes during sleep, correlated with the severity of hypoxaemia $[127,128]$ or measures of sleep fragmentation [129]. In a large clinical series of CAD patients, episodes of ST-segment depression occurred in about one-third of the sample, but a tight temporal relationship between apnoeas and ECG changes could not be demonstrated [130], supporting the interpretation that additional factors are likely to be involved in the pathogenesis of symptomatic coronary events in OSAS patients [131]. At present, the clinical meaning and relevance of the described changes remain undefined [132].

In summary, epidemiological and clinical studies show that the association of OSAS and CAD is frequent and possibly relevant for prognosis. The mechanism(s) by which OSAS exerts its detrimental effect remain to be established and future studies should actively pursue the identification of OSAS patients at high cardiovascular risk.

\section{Stroke}

Epidemiological data suggest a strong relationship between OSAS and acute cerebrovascular events. The prevalence of SDB in patients with acute stroke ranges $44-72 \%$ in different series, and after the acute phase still remains higher than in the general population $[133,134]$. The evidence for an association between stroke or transient ischaemic attacks and a history of heavy snoring or polysomnographic evidence of obstructive sleep apnoeas has been recently summarised in patients with acute stroke [133, 134]. Moreover, the potential value of obtaining a polysomnographic recording [135] and a costeffectiveness analysis of OSAS diagnosis and treatment [136, 137] has also been carried out in patients with acute stroke.

Prospective data from the Wisconsin Sleep Cohort clearly indicate that an AHI $\geqslant 20$ was associated with a four-fold increase in the risk of stroke during a 4-yr follow-up study, supporting the view that SDB precedes, and does increase the risk for, the occurrence of stroke after OSAS diagnosis [138]. In the Caerphilly Cohort (UK), a high risk for stroke over a 10-yr follow-up was found in males reporting more than one of the following symptoms: snoring, witnessed apnoeas, daytime sleepiness, insomnia, and restless legs [139]. Finally, increasing incidence of stroke and death with OSAS severity was found in a cohort of OSAS patients after a median follow-up of 3.4 yrs [51]

Some uncertainties on the role of OSAS in the pathogenesis of stroke are due to the fact that SDB can precede but also follow occurrence of stroke [140]. A pathogenetic involvement of OSAS in cerebrovascular disease is suggested by the direct relationship found between the severity of nocturnal oxygen desaturation and intima-media thickness and/or the occurrence of atherosclerotic plaques in the carotid arteries of OSAS patients, independent of occurrence of hypertension [141, 142]. Moreover, central but not obstructive sleep apnoeas decrease during recovery after a stroke or a transient ischaemic attack, suggesting that obstructive events are most likely to pre-date the cerebrovascular event [143]. However, an independent association of OSAS with transient ischaemic attacks has been reported in some but not all studies [143-145], and any temporal relationship between OSAS and cerebrovascular events should still be considered as undefined.

Given the established association of OSAS and hypertension, it is quite surprising that little is known on the time course of blood pressure in patients with stroke, according to the presence or absence of SDB. According to a recent report, the mean 24-h blood pressure level in patients with acute stroke positively correlated with severity of sleep apnoea, while the nondipping status (i.e. a nocturnal reduction $<10 \%$ of the daytime blood pressure value) was associated with the severity of stroke [146]. These data refer to a time period when central events are prevalent, and no data are available on circadian blood pressure profile in patients with OSAS after stroke.

OSAS could worsen prognosis after a stroke episode, as suggested by the high mortality of patients with an AHI $>30$ after stroke [147], and the improvement in 18-month survival 
of those OSAS patients $(\mathrm{AHI} \geqslant 20$ ) who were able to tolerate CPAP treatment after stroke [148]. In addition, sleep apnoea may increase the risk of recurrence of ischaemic stroke [149]. Patients with stroke and sleep apnoea show more severe functional impairment and longer hospitalisation during rehabilitation compared with patients without SDB [150].

Recently, BASSETTI et al. [151] reported follow-up data in a large series of stroke patients. The study found that SDB (AHI $\geqslant 30$ ): 1) was associated with diabetes, night-time stroke onset and macro-angiopathy as a cause of stroke; 2) improved after the acute phase; 3) was associated with increased post-stroke mortality; and 4) could be treated with long-term CPAP in $\sim 10 \%$ of patients. This patient sample cannot be considered as representative of an unselected population of patients with stroke, possibly explaining some differences compared with other studies. However, the observations provided could serve to design a large randomised trial on the effects of treatment of OSAS in patients with cerebrovascular disease [151].

Careful case-control studies have tested whether OSAS might be associated with silent cerebrovascular disease, with mixed results [152, 153]. Brainstem white matter disease was hypothesised to be more common in OSAS than non-OSAS patients, but it correlated with arousal frequency only, in almost 800 elderly participants of the Sleep Heart Health Study [154], and the clinical significance of this remains unclear. Conversely, altered metabolism in the frontal white matter was shown in OSAS patients with and without clinically evident cardiovascular involvement, suggesting that OSAS affects brain function independent of vascular damage [155].

In summary, evidence for the association of SDB with cerebrovascular disease mostly relates to the pathophysiology of acute events. Current knowledge is still limited on the role of long-term SDB and on possible modifications of the natural history of stroke by CPAP treatment in patients with both SDB and stroke. Finally, even though not necessarily implying a stroke, OSAS might predispose to death during sleep in critically ill patients by increasing arousal threshold and lengthening apnoeic episodes causing cerebral hypoxaemia [156].

\section{Heart failure}

The relationship between OSAS and heart failure (HF) is complex. On the one hand, obstructive sleep apnoeas negatively affect cardiac function acutely and may cause cardiac remodelling in the long term, thus possibly contributing to the pathogenesis of HF. On the other hand, HF could contribute to the pathogenesis of SDB in the form of either obstructive or central apnoeas [157-160]. Assessing the impact of the association of OSAS and HF is clinically relevant, due to the rising prevalence of $\mathrm{HF}$ and the availability of effective treatment for OSAS. However, whether CPAP treatment may favourably affect long-term prognosis and quality of life in patients with OSAS and HF is still unknown as available data have only reported a 1-3-month follow-up [161].

Relatively few studies are available on the association of OSAS and HF. In studies of patients with HF, the prevalence ranged 11-53\% [162-165]. Cross-sectional data from the Sleep Heart Health Study showed a strong association of SDB with HF (odds ratio for upper versus lower quartile 2.38, confidence interval 1.22-4.62) [113].
Obstructive sleep apnoeas acutely affect cardiac function. Intrathoracic pressure swings during respiratory efforts increase venous return and ventricular afterload, while sympathetic activation secondary to hypoxia and arousal increases blood pressure and myocardial oxygen consumption at the end of apnoeas. The increase in cardiac load during obstructive apnoeas also occurs in the normal heart as shown in animal models [166], but its consequences are particularly striking in the failing heart. Accordingly, both the Mueller manoeuvre and obstructive apnoeas have been shown to acutely depress cardiac function especially in patients with heart failure [167, 168]; these effects were acutely reversed by CPAP application [168].

In the long term, OSAS favours the development of systolic dysfunction [166, 169]. In randomised controlled studies in patients with HF and OSAS, CPAP treatment for a few weeks increased left ventricular ejection fraction and decreased blood pressure and sympathetic activation, strongly suggesting a pathogenic role of OSAS in worsening cardiac function [170172]. However, whether the positive effects of CPAP on the cardiovascular system may also imply an improvement in long-term prognosis of patients with OSAS and HF is still unknown [173]. An interesting point, critically discussed by ARZT et al. [161], is the clinical relevance of EDS in the therapeutic approach of patients with HF and OSAS. An improved quality of life after CPAP treatment has only been documented in OSAS patients with EDS [171]. More data on patients with HF and OSAS but no EDS are needed to improve clinical decision making for the treatment of OSAS. In addition, interpreting clinical data is complicated by the increased prevalence of HF with the progressive ageing of the population and by the rapid evolution in the treatment of HF. At present, the impact of OSAS on long-term survival appears small in patients with severe HF [173] or in elderly subjects [35, 174]. Therefore, large clinical studies in well-characterised samples are necessary to obtain conclusive information on the prognostic role, if any, of OSAS in HF.

OSAS may contribute to the pathophysiology of HF by potentiating sympathetic activation. Patients with $\mathrm{HF}$ and sleep apnoea show higher daytime muscle sympathetic nerve activity (MSNA) compared with patients with HF but no sleep apnoea [175]. CPAP treatment in patients with HF and OSAS decreased daytime MSNA, systolic blood pressure and heart rate [176], suggesting a significant contribution of OSAS to increased central sympathetic outflow. However, other studies on noradrenaline spillover in HF patients without apnoeas, with OSAS or with central sleep apnoeas (CSA), respectively, found similar spillover rates in the first two groups, while increased spillover in patients with CSA was entirely accounted for by a more severe cardiac disease [177]. While differences in patient characteristics or methodology may account for different results among studies, this area deserves further investigation because of its potential clinical impact on the treatment of $\mathrm{HF}$.

\section{Arrhythmias}

Since the earliest clinical observations, OSAS has been recognised as a potential cause of arrhythmias during sleep [9, 178-181]. Bradyarrhythmic episodes occur in OSAS patients, possibly reflecting reflex parasympathetic activity 
evoked by apnoeas; GUILLEMINAULT et al. [182] reported bradyarrhythmias in $18 \%$ of OSAS patients and BECKER et al. [180] reported heart block episodes in $20 \%$ of patients with OSAS, especially when OSAS was severe. Subsequent studies from the same group confirmed these findings and underlined the trend for bradyarrhythmias to occur in REM sleep and disappear during CPAP treatment [183, 184]. More recently, recordings obtained for several consecutive weeks have documented bradyarrhythmia in $47 \%$ of patients with untreated OSAS with a large intra-individual variability accounting for the higher prevalence compared with previous studies [185] and possibly for some negative results by previous investigations based on single-night Holter recordings [186]. Furthermore, CPAP therapy abolished pathological dysrhythmias in OSAS patients within a period of 24-48 h [187]; long-term recordings also documented disappearance of arrhythmias after a few weeks of CPAP treatment [184]. A high prevalence of OSAS was found in patients in whom Holter recordings showed isolated bradyarrhythmias during sleep [188]. In such patients, a sleep study is warranted before implanting a pacemaker because CPAP therapy may be sufficient to prevent arrhythmias associated with OSAS [188].

However, not all studies reported a significant association between heart rhythm disturbances requiring implantation of a pacemaker and SDB [189]. In addition, few studies are available on bradyarrhythmias associated with SDB in the general population. In subjects from the Sleep Heart Health Study, no significant difference was shown for conduction delay arrhythmias between SDB-exposed and -nonexposed groups, but second-degree atrioventricular block type 1 and the percentage of pacemaker-implanted subjects tended to be higher in the group with an AHI $\geqslant 30$ [190].

Other studies have tested the hypothesis that OSAS might increase the prevalence of nocturnal ventricular arrhythmias through intermittent hypoxia during sleep. The only population study on this topic reported increased odds ratios for ventricular tachycardia and complex ventricular ectopy in patients with moderate-to-severe OSAS compared with nonOSAS subjects [190]. In addition, ventricular premature beats decreased by $58 \%$ after 1 month of CPAP treatment in patients with OSAS and HF [191]. These data are in agreement with the expected effects of hypoxaemia on the heart [179] and may help explain the pathogenesis of nocturnal sudden death in OSAS patients [58,59].

The association of OSAS with atrial fibrillation, and the possibility that atrial pacing might improve SDB, are recent areas of clinical research. A high prevalence of OSAS has been found in patients with atrial fibrillation by some [192, 193] but not all studies [194]. Case reports have shown the shift from sinus rhythm to atrial fibrillation during sleep in patients with untreated OSAS [195], and the disappearance of atrial fibrillation and heart block after initiation of CPAP treatment in severe OSAS [196]. A pathogenetic role of OSAS is further suggested by the four-fold increase in the prevalence of atrial fibrillation in subjects with an AHI $\geqslant 30$ reported by the Sleep Heart Health Study Investigators [190]. Finally, the clinical relevance of the role of OSAS in atrial fibrillation is indicated by the high rate of recurrence of atrial fibrillation in inadequately treated OSAS patients [197]. However, atrial fibrillation is also a risk factor for central sleep apnoea [163-165], suggesting that its association with OSAS may reflect a general effect of sleep apnoeas rather than being specific for OSAS.

Atrial overdrive pacing was proposed as a possible therapeutic approach for sleep apnoea in an intriguing study by GARRIGUE et al. [198], who reported that AHI decreased when patients were subjected to pacing compared with baseline conditions. These results were not confirmed by subsequent studies [199203], even though the pathophysiology of cardiac pacing in SDB is still considered of interest, especially in HF patients [204, 205].

\section{METABOLIC DERANGEMENTS IN OSAS AND RELATIONSHIP TO CARDIOVASCULAR DISEASE}

Besides the improved understanding expected from large clinical and epidemiological studies concerning the natural history of OSAS, and the largely unproven effects of treatment options other than CPAP, one of the most interesting and promising areas of current clinical and experimental research regards the inter-relationships between OSAS, energy metabolism [30,31] and sleep deprivation [206]. Complex hormonal interactions involve sleep and metabolism, and current lifestyle affects sleep-wake cycles, with the toll of progressively decreasing sleep times, at all ages, compared with previous decades. Several review papers have recently been published on the relationship between OSAS and the metabolic syndrome [30, 31, 206-210], with special regard to the pathogenesis of increased cardiovascular risk. Increasing evidence indicates that OSAS and intermittent hypoxia may independently affect energy metabolism. The following subsections summarise data on: 1) insulin resistance in population and patient studies, and the effects of CPAP treatment; 2) the association of OSAS and diabetes; and 3) lipid metabolism and hepatic steatosis in OSAS.

\section{Insulin resistance}

IP et al. [211] reported that markers of OSAS severity (AHI and minimum oxygen saturation) were associated with insulin resistance, whilst PUNJABI et al. [212] reported that, in mildly obese but otherwise healthy males from the general population, SDB was associated with insulin resistance. Crosssectional data from the Sleep Heart Health Study and the Wisconsin Sleep Cohort found similar results in population cohorts [213, 214]. However, the longitudinal data from the Wisconsin Cohort could not demonstrate a clear relationship between SDB and the subsequent development of diabetes [214]. Other studies in snorers have confirmed the association of SDB and insulin resistance or diabetes in Korean nonobese [215] and Indian males [216]. In all studies, the association was independent of obesity, even though obesity is known to increase the risk for impaired glucose tolerance. Similar results were found in subjects with suspected OSAS [217-219] and by some [220] but not all [221, 222] studies in children with SDB. In normal subjects, hypoxia appears to be an important contributor to glucose intolerance [223]. Treatment with CPAP rapidly restored insulin sensitivity, especially in patients who were not obese [224], but a paradoxical increase in glucose level was also documented during acute CPAP application in nondiabetic obese OSAS patients [225]. In summary, the bulk of evidence supports the view that OSAS worsens glucose metabolism, but this effect was reversible with treatment. 


\section{Type-2 diabetes}

The association of OSAS and type-2 diabetes was reported much earlier than the studies on insulin resistance, but the evidence was limited to small case series or epidemiological studies using snoring as a surrogate marker for OSAS [226]. More recent epidemiological studies have convincingly shown that type-2 diabetes is often associated with OSAS and daytime sleepiness [210-213, 227-229]. For example, in a large series of OSAS patients, type- 2 diabetes and impaired glucose tolerance showed a 30 and 20\% prevalence, respectively [218], and studies in snorers reached similar conclusions [230-232]. In prospective studies, the risk of developing diabetes was higher in snorers than nonsnorers [233, 234], especially in obese subjects [233]. However, insulin sensitivity improved after CPAP treatment in diabetic OSAS patients [235-238]. Sleep apnoeas are also frequent in children with type-1 diabetes [239] and adult patients with diabetic neuropathy [240,241], but this probably reflects the consequence of abnormalities of ventilatory control associated with diabetes rather than a direct effect of obstructive apnoeas [242-244].

\section{Lipid metabolism and hepatic steatosis}

Altered lipid metabolism and hepatic steatosis in OSAS have been recently studied. Total cholesterol tended to decrease after CPAP treatment [245]. It is also possible that HDL-C in OSAS patients is functionally less effective in preventing lowdensity lipoprotein oxidation in vivo [246]. Mean HDL-C increased after CPAP treatment and this change correlated with the decrease in AHI [247], suggesting reversibility of OSAS-associated changes in plasma lipids. As for the prevalence of hepatic steatosis in OSAS patients, insulin resistance and nonalcoholic steatohepatitis (NASH) often occur in obese and diabetic subjects [248], and OSAS might contribute to NASH pathogenesis similar to its role in insulin resistance. Available data, although limited, indeed suggest this might be the case. According to SiNGH et al. [249], the prevalence of OSAS was $\sim 50 \%$ in patients with nonalcoholic fatty liver disease, while severe OSAS represented a risk factor for increased liver enzymes and steatohepatitis independent of body weight [250]. One in three obese OSAS patients showed abnormal serum aminotransferase levels, reverting towards normal values during prolonged CPAP treatment [251]. In addition to clinical data, experimental studies also suggest a role of intermittent hypoxia in the pathogenesis of hyperlipidaemia $[252,253]$, supporting an independent role of OSAS, in addition to obesity, in the pathogenesis of NASH [254, 255].

\section{BASIC MECHANISMS OF CARDIOVASCULAR DISEASE IN OSAS}

The mechanisms underlying cardiovascular disease in patients with OSAS are still poorly understood. The pathogenesis is likely to be a multifactorial process involving a diverse range of mechanisms including sympathetic nervous system overactivity, selective activation of inflammatory pathways, endothelial dysfunction and metabolic dysregulation, with the latter particularly involving insulin resistance and disordered lipid metabolism.

\section{Sympathetic nervous system overactivity}

The repetitive episodes of upper airway obstruction that are characteristic of OSAS result in intermittent hypoxia and large swings in intrathoracic pressure that trigger autonomic responses including sympathetic nervous system overactivity. Many reports have demonstrated sympathetic overactivity in patients with OSAS. Increased urinary catecholamine levels have been reported in patients with OSAS with levels falling after treatment by tracheostomy [256]. A direct link between hypoxaemia and elevated sympathetic activity has also been proposed [257-259] and elevated MSNA was attenuated during apnoea when hyperoxic conditions were maintained [258]. Furthermore, NARKIEWICZ et al. [260] have demonstrated a selective potentiation of peripheral chemoreflex sensitivity in patients with OSAS compared with normal controls. Other reports have indicated a significant fall in both plasma and urinary catecholamines following nasal CPAP therapy [261263]. MSNA has also been directly measured by insertion of a tungsten microelectrode into the peroneal nerve. Using this methodology, an increase in MSNA following an acute apnoea associated with hypoxia has been observed [264], together with positive correlations between MSNA and plasma noradrenaline levels $[265,266]$. Treatment with nasal CPAP significantly lowered MSNA [267].

Furthermore, evidence in favour of a significant contribution to the pathogenesis of OSA-related cardiovascular complications, by alterations in autonomic cardiovascular control, has been obtained by techniques exploring spontaneous sensitivity of baroreflex control of the heart [268, 269]. OSAS patients are characterised by reduced baroreflex sensitivity during both wakefulness and sleep [270] and such impairment can be reversed by CPAP. This improvement is particularly evident with chronic treatment [89], although a small but significant improvement can also be detected even after short-term CPAP application [271].

Support for the role of sympathetic overactivity in the pathogenesis of hypertension in OSAS also comes from animal models. In both dog and rat models of OSAS, an increase in blood pressure was found, which declined once the airway occlusion was abolished $[78,80]$. These blood pressure changes were not observed with recurrent induced arousals without airway occlusion, indicating that it was the obstructive events rather than the associated arousals that were responsible for the observed effects [78]. These changes in blood pressure were prevented by pharmacological and surgical blockade of the sympathetic nerve system in a rat model of chronic intermittent hypoxia [272, 273].

\section{Inflammation}

Systemic inflammation plays an important role in all stages of atherosclerosis. It occurs in the vasculature as a response to injury, lipid peroxidation, and perhaps infection. Two wellrecognised markers of systemic inflammation have been evaluated in OSAS, namely C-reactive protein (CRP) and tumour necrosis factor (TNF)- $\alpha$. CRP, an important serum marker of inflammation, is synthesised by the liver and regulated by cytokines, particularly interleukin (IL)-6 [274]. Prospective studies have shown that CRP is a strong predictor of future coronary events in apparently healthy males and females [275] in addition to peripheral arterial disease [276]. OSAS was reported to be associated with higher CRP and IL-6 levels in otherwise healthy subjects, and these levels correlated with OSAS severity, supporting an important role for 
inflammation in the cardiovascular pathogenesis of the disease [277-280]. Furthermore, treatment with nasal CPAP has been reported to be associated with decreased levels of these markers [278]. However, recent studies have failed to find an association between CRP and OSAS and the relationship is now less clear [281, 282]. It is likely that studies involving large numbers of patients, adequately controlled for potential confounding factors, particularly obesity, will be required to finally resolve the question of a possible independent association.

TNF- $\alpha$ is another inflammatory cytokine, which is regulated by the transcription factor nuclear factor $(\mathrm{NF})-\kappa \mathrm{B}$, a master regulator of inflammatory gene expression [283], and contributes to atherogenesis [284]. TNF- $\alpha$ levels have been reported to correlate with cardiovascular risk [285]. TNF- $\alpha$ levels are elevated in OSAS and fall with CPAP therapy [286, 287] and both T-cells and monocytes have been reported as potential sources of this cytokine [288]. Furthermore, a gene polymorphism associated with increased TNF- $\alpha$ production has recently been reported to be more common in OSAS [289].

Recent evidence from a cell culture model of intermittent hypoxia supports a selective activation of inflammatory pathways over adaptive pathways in response to intermittent hypoxia, which contrasts with sustained hypoxia where activation of adaptive and protective pathways predominate [287]. This preferential activation of inflammatory pathways may be a consequence of the intermittent re-oxygenation that is characteristic of intermittent hypoxia and thus represents a variant of reperfusion injury [290]. The activation of inflammatory transcription factors by intermittent hypoxia/re-oxygenation (IHR) has also been demonstrated in a rat model and the authors found a significant correlation with the degree of IHR and neurocognitive function, and also an improvement with reversal of IHR [291].

Levels of circulating soluble adhesion molecules, which mediate adhesion of leucocytes to the vascular endothelium, such as intracellular adhesion molecule-1, are elevated in patients with OSAS and improve with CPAP therapy [292]. Furthermore, increased adhesion of lymphocytes to vascular endothelial cells has been demonstrated in OSA patients compared with controls [293]. Inflammatory cytokines, such as TNF- $\alpha$ and IL-8 induce the expression of cellular adhesion molecule [294, 295], thus providing further evidence of an important role for inflammation in the cardiovascular morbidity of OSAS.

Hypoxia also induces the activation of the adaptive pathway mediated by upregulation of the transcription factor hypoxiainducible factor (HIF)-1. There is evidence of HIF-1-dependent gene activation in OSAS as indicated by increased levels of vascular endothelial growth factor [296], although another report indicates that OSAS associated with pure intermittent hypoxia (where interapnoea oxygen levels are normal) is not associated with elevated levels of another HIF-1-dependent gene, erythropoietin [287].

\section{Oxidative stress}

While there is evidence of increased release of reactive oxygen species in patients with OSAS [297, 298], as a likely consequence of intermittent re-oxygenation associated with recurring apnoea, the interaction with other molecular mechanisms such as inflammatory pathways has not been fully evaluated. Studies in rats have demonstrated that chronic intermittent hypoxia $(\mathrm{CIH})$ results in oxidative stress that subsequently leads to left ventricular dysfunction [299]. Similarly, CIH-associated oxidative stress has been shown to result in cortical neuronal cell apoptosis in mice [300]. The oxidative stress-induced brain injury appears to be associated with hypersomnolence in a mouse model of $\mathrm{CIH}[301,302]$. Oxidative stress may be responsible for reduced nitric oxide (NO) bioavailability, enhanced lipid peroxidation [303] and formation of isoprostanes [304], although there is recent evidence that $\mathrm{CIH}$ is associated with activation of inducible NO synthase in the brain [305]. $\mathrm{CIH}$ has also been associated with reduced hypoglossal nerve output by oxidative stress [306]. Furthermore, free radicals might upregulate transcription factors such as NF- $\mathrm{kB}$ and HIF [290].

\section{Endothelial dysfunction}

Vascular endothelium controls various vascular functions through regulation of vasoactive mediators in response to physical or biochemical stimuli and is the major regulator of vascular haemostasis. The endothelium maintains the balance between vasodilatation and vasoconstriction; if this balance is tilted towards vasoconstriction, endothelial dysfunction occurs, causing damage to the arterial wall. Endothelial dysfunction has been found to occur in response to cardiovascular risk factors and to precede or accelerate the development of atherosclerosis [284]. Such dysfunction appears to have a predictive value for cardiovascular events in patients with chest pain and/or coronary artery disease [307]. Endothelial dysfunction has also been shown to occur in OSAS patients with little evidence of cardiovascular disease in human studies that assessed intima-media thickness and carotid-femoral pulse-wave velocity [308]. A role for this dysfunction in the pathogenesis of cardiovascular complications in OSAS has been supported by various studies demonstrating impairment in endothelium-dependent vasodilatation [309-313]. Furthermore, treatment with nasal CPAP has been reported to reverse endothelial dysfunction [314]. There appears to be a sex difference in endothelial function in that flow-mediated vasodilation is more impaired in females with OSAS than males [315].

A major vasodilator substance released by the endothelium is $\mathrm{NO}$ [316], and decreased production or activity of NO may be an early sign of atherosclerosis. Decreased levels of NO have been found in OSAS patients and levels increase with CPAP therapy [317-322]. The endothelium also produces vasoconstrictor substances, such as endothelin and angiotensin II, and levels have been reported as increased in OSAS and to fall with effective CPAP therapy [323]. However, other reports did not find an increase of endothelin in OSAS [324]. The Sleep Heart Health Study has also reported evidence of vascular dysfunction among older participants, particularly arterial diameter [325], identifying OSAS as an independent risk factor for impaired flow-mediated vasodilation. However, endothelial dysfunction is often seen in patients with hypertension, hyperlipidaemia, diabetes or smoking and these comorbidities may limit the importance of OSAS as an independent risk factor for endothelial dysfunction. 


\section{Blood coagulation abnormalities}

Increased cardiovascular risk in OSAS patients may also be linked to abnormalities of coagulation and excessive platelet activation and this topic has been recently reviewed [326]. Increased circulating levels of activated coagulation factors have been reported by ROBINSON et al. [245] in untreated OSAS patients, but CPAP treatment appeared not to modify them. Interestingly, two groups have recently reported an increased D-dimer level in untreated OSAS and its correlation with the severity of nocturnal hypoxaemia, suggesting that a hypercoagulable state is potentially involved in cardiovascular risk in OSAS patients [327, 328]. Other investigators have found the following: 1) increased blood viscosity in untreated adult OSAS [329]; 2) increased fibrinogen level in both adults [329] and children with SDB [330]; and 3) evidence of platelet activation, which decreased after CPAP treatment [331, 332]. However, some uncertainties still remain on the independent role of OSAS on increased blood coagulability, due to the common coexistence of other cardiovascular risk factors [331], the lack of correlation between markers such as fibrinogen and severity of SDB in children [330] and the incomplete normalisation of coagulation after CPAP treatment [245, 331].

\section{Metabolic dysregulation}

The detailed clinical and epidemiological evidence concerning metabolic dysregulation in OSAS has been discussed above. OSAS-related factors that may contribute to metabolic dysregulation include increased sympathetic activity, sleep fragmentation and intermittent hypoxia.

\section{Glucose intolerance}

The mechanisms of impaired glucose tolerance in OSAS particularly involve insulin resistance. A number of reports have found increased insulin resistance and impaired glucose tolerance in OSAS patients, independent of body weight [211, $333,334]$, and a worsening of insulin resistance with increasing AHI [212]. In nondiabetic OSAS patients, circulating advanced glycation end-products have been reported to correlate with the severity of intermittent hypoxia [335] and a cause-effect relationship between hypoxia and glucose intolerance has been shown by studies in healthy humans [223]. Animal studies also support an important role for intermittent hypoxia in the development of insulin resistance, which appears to be dependent on the disruption of leptin pathways [336].

\section{The leptin pathway}

Leptin is an adipocyte-derived hormone that regulates body weight through the control of appetite and energy expenditure. Leptin may predispose to platelet aggregation and has been implicated as an independent cardiovascular risk factor [337]. Leptin has been extensively studied in recent years due to its role in appetite regulation [338], but its functions are probably more complex than initially believed. Human obesity is associated with increased leptin levels and a state of leptin resistance, while lack of leptin causes obesity in animal models [339]. Leptin likely exerts pleiotropic functions in OSAS, not only by its effects on metabolism and obesity, but also by affecting ventilatory control [339]. Expression of the human leptin gene is regulated by hypoxia [340]. Hypercapnic OSAS patients also show a higher degree of leptin resistance compared with nonhypercapnic subjects [341], and similar data have been reported in obese non-OSAS subjects [342].

Several studies have reported that OSAS is associated with hyperleptinaemia, although some were not adjusted for obesity and visceral fat distribution. One study reported that elevated leptin levels in OSAS were only found in obese subjects [343], whereas other reports found that sleep hypoxaemia was the principal determinant [344]. A report from the Cleveland family study also demonstrated BMI to be an important confounding factor in the relationship between OSAS and leptin levels [345]. Effective treatment with CPAP has been reported to be associated with a decrease in leptin levels [346, 347], although in one report the fall in leptin levels was only observed in nonobese patients [347]. The study by SHIMIZU et al. [348] was particularly interesting as changes in plasma leptin levels were related to cardiac sympathetic function and, thus, sought to link different pathogenetic mechanisms of cardiovascular complications in OSAS. While the results were not conclusive, the findings indicated a significant fall in leptin levels with CPAP therapy. However, another report found that leptin levels, when adjusted for body fat distribution, were not related to indices of OSAS [349] and a further study indicated that leptin levels were more closely associated with indices of obesity and lipid dysfunction than with indices of OSAS [350]. Thus, the possibility of an independent relationship of leptin and other adipocytokines (such as adiponectin and ghrelin) to OSAS requires further investigation.

\section{PRIORITIES FOR FUTURE RESEARCH General priorities}

While substantial progress has been made, particularly in recent years, in the identification of possible mechanisms to explain the association between OSAS and cardiovascular disease, substantial deficits remain. Many of the studies to date, particularly those related to identifying the basic mechanisms involved in these associations, have suffered from small sample size, inadequate control populations and failure to adequately control for potential confounding variables such as body mass index (BMI). Thus, it is not surprising that conflicting findings have been reported in many of these studies. There have been few translational studies that have explored basic mechanisms of cardiovascular disease in OSAS and applied the findings to the clinical setting.

In general terms, there is a clear need for large-scale collaborative studies of carefully defined patient populations with OSAS that are adequately controlled for potential confounders. Such large-scale studies carry the prospect of evaluating potential interactions between different basic mechanisms operating in OSAS and cardiovascular disease, and including interactions with other related disorders such as diabetes and dyslipidaemia. Studies that explore the interaction of several factors that could lead to the development of cardiovascular disease in OSAS are singularly lacking. For example, insulin affects both NO release and the sympathetic nervous system, and sleep deprivation contributes to the development of insulin resistance. Possible strategies could be as follows: 1) inclusion of large samples with various degrees of confounding factors including obesity, central obesity and other elements of the metabolic syndrome that may not be 
solely related to OSA; or 2) studying highly selected subgroups, such as lean subjects with severe OSA and limited risks factors otherwise.

Furthermore, prospective studies of carefully defined patient cohorts would likely provide important information on the evolution of cardiovascular disorders in OSAS patients, but the recognised efficacy of CPAP in treating the disorder makes long-term randomised studies difficult to design because of the potential dangers of withholding effective therapy from severely affected patients, particularly accident risk. Special attention should be paid to respiratory disorders during sleep in specific patient categories.

\section{Children}

In children, the prevalence of obesity, metabolic syndrome and type-2 diabetes are rising [351, 352]. As a consequence, the prevalence of OSAS can be expected to shift towards younger ages if the current trend towards sedentary lifestyle and excess caloric intake is not reversed with effective interventions aimed at the young population. Conversely, in past decades, OSAS in children was considered as a mostly mechanical problem of upper airways secondary to adenotonsillar hypertrophy, easily solved by surgery and useful to study the clinical effects of upper airway obstruction free from the many confounders typically associated with OSAS in adults.

\section{The elderly}

In elderly subjects, obstructive apnoeas during sleep are quite frequent but their clinical and prognostic impact appears lower than in young to middle-aged subjects $[32,353]$. This finding, especially puzzling given that common comorbidities in the elderly would be expected to further worsen disease outcome, has led some authors to hypothesise that nocturnal intermittent hypoxia might activate chronic protective mechanisms against cardiovascular damage similar to those described for classic ischaemia-reperfusion damage [354]. Survival bias and lack of clinical information on sleep apnoea in subjects who die because of acute cardiovascular events are alternative possible explanations for the apparent decrease in the consequences of OSAS in the elderly.

\section{Females}

Studies on OSAS and cardiovascular risk have predominantly assessed male, middle-aged, obese patients with severe OSAS, leaving many questions still open on the pathophysiology of OSAS in females [355, 356]. In pre-menopausal females, hormonal influences may directly or indirectly (by influencing body fat distribution) protect the female sex from increased collapsibility of the upper airway and account for the low prevalence and severity of OSAS in females compared with BMI-matched males [357]. Nevertheless, SDB often occurs in late pregnancy [358] and may contribute to the pathophysiology of pre-eclamptic states [359] by potentiating cardiovascular responses to respiratory events during sleep or endothelial dysfunction [360, 361]. Markers of endothelial dysfunction appear more strongly associated with SDB severity in females compared with males [315], but the contribution of obstructive sleep apnoea to hypertension may be lower in females compared with males [64]. A role of sex hormones is suggested by the increased risk to develop sleep apnoea in the post-menopausal period apparently prevented by use of hormonal replacement therapy [33, 362, 363]. Little is known about possible sex-related differences in the prognosis of OSAS, but a preliminary report from the Wisconsin Sleep Study suggested a much higher mortality rate in females compared with males with OSAS of comparable severity [364].

The foregoing account indicates that the basic mechanisms involved in the pathogenesis of cardiovascular disease in OSAS are complex and some aspects, particularly those related to the molecular mechanisms of intermittent hypoxia, may be more suited to cell culture and/or animal models. In addition, current knowledge on the interactions between genetic background and environmental factors in the pathogenesis of OSAS is still limited. Future studies will help clarify the interactions between putative OSAS genes and disruption of cardiovascular regulation or body weight control in individual patients [365]. A schematic outline of future research priorities is proposed in figure 1.

\section{Specific priorities}

Inflammatory molecular pathways

While there is emerging evidence that inflammatory pathways play an important role in the evolution of atherogenesis and subsequent vascular disease, the precise mechanisms remain to be elucidated. In particular, the balance between different molecular mechanisms of inflammation such as TNF- $\alpha$ and $\mathrm{CRP}$, remains unclear, as does the interaction of inflammatory and adaptive molecular pathways, such as those involving NF$\kappa \mathrm{B}$ and HIF-1, respectively. There is emerging evidence that intermittent hypoxia plays a central role in these mechanisms via the effects of intermittent re-oxygenation, which is an integral feature of intermittent hypoxia, and possibly involving the generation of ROS. Additional studies involving cell culture models and translational studies involving bench, animal and human models are required to adequately explore the mechanisms involved.

\section{Sympathetic excitation}

Evidence has accumulated over the past decade of an important role for sympathetic nervous system overactivity in the pathophysiology of vascular dysfunction in OSAS, which appears to be relieved by CPAP therapy. However, the underlying mechanisms remain unclear, particularly the role of intermittent hypoxia and sleep fragmentation and the effects on different types and sizes of blood vessels. Animal models may be most suited to this area of investigation. Furthermore, the importance of sympathetic nervous system over activity in hypertension in general is still under debate; current evidence suggests a role in the later rather than earlier stages of disease development. Further controlled studies, involving larger groups of subjects and allowing for potential confounding factors are necessary to more clearly define the role of sympathetic excitation in the pathophysiology of cardiovascular complications in OSAS.

\section{Hypercoagulability/thrombosis}

While platelet dysfunction and/or hypercoagulability play an important role in the pathogenesis of vascular disease, there are limited studies on the potential role of hypercoagulability in the development of vascular disease in OSAS. However, 


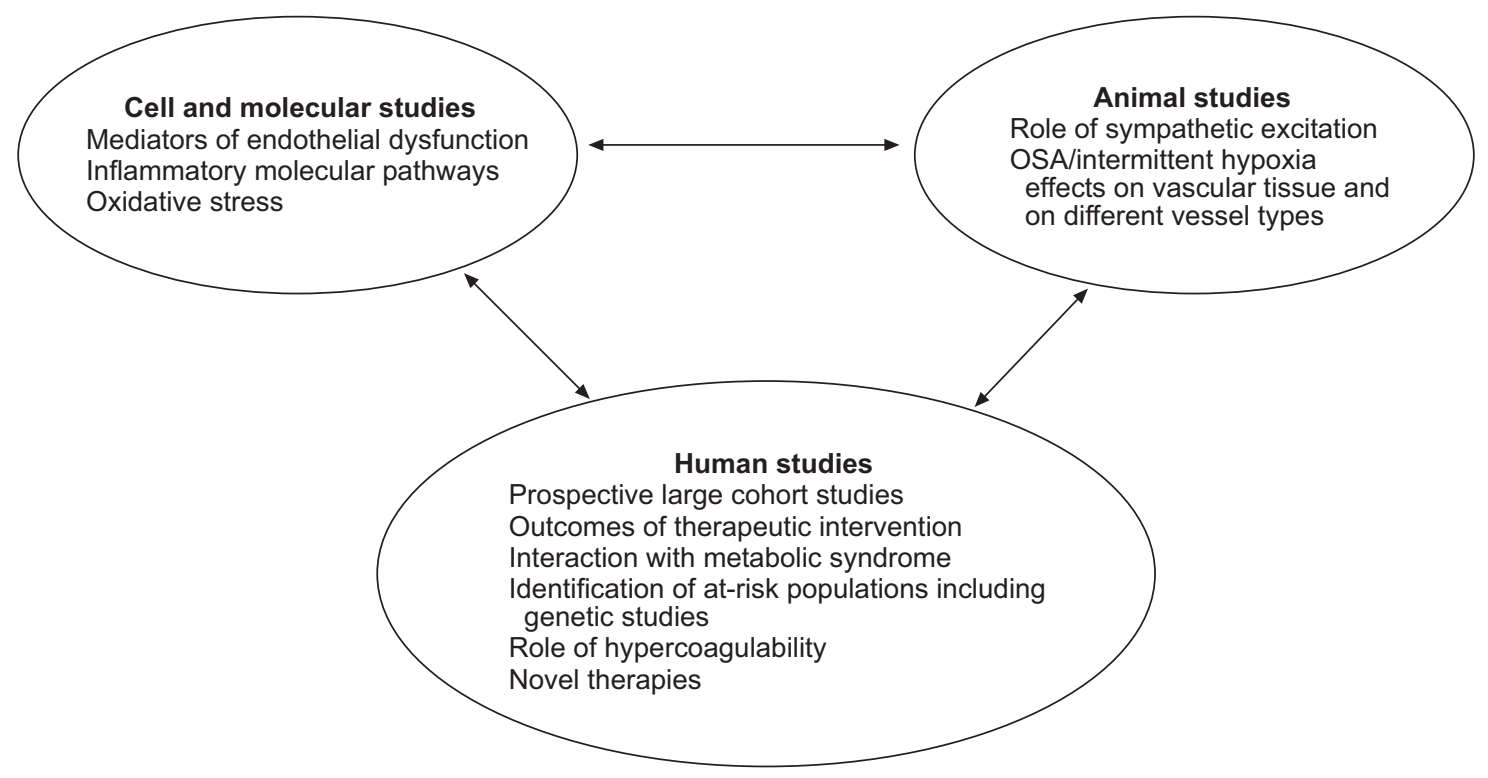

FIGURE 1. Future research priorities for obstructive sleep apnoea (OSA) syndrome.

published reports demonstrating a potential link between hypercoagulability and OSAS indicate this to be a potentially important area for further study.

\section{Endothelial dysfunction}

Endothelial dysfunction is an important precursor of atherosclerosis and subsequent vascular disease and there is emerging evidence of such dysfunction in OSAS. To date, however, studies have been limited and there is little information on potential interaction of vasoactive substances such as NO and other molecular mechanisms involving inflammation.

\section{Metabolic dysregulation}

While there is now good evidence that OSAS is associated with insulin resistance, independent of potential confounders, the detailed mechanisms of this relationship have not been identified. There is some evidence that intermittent hypoxaemia may be more important than other indices of OSAS. Furthermore, while there is evidence from several reports of abnormal lipid metabolism in OSAS, particularly relating to leptin, the detailed mechanisms remain to be identified.

\section{CONCLUSION}

Obstructive sleep apnoea syndrome and cardiovascular disease are highly prevalent in the European population and there is now convincing evidence that obstructive sleep apnoea syndrome is an independent risk factor for hypertension, ischaemic heart disease, and probably stroke. However, there is a need to collect more epidemiological data in Europe taking into account both sex- and age-related issues. The ongoing Action for the Cooperation in the field of Scientific and Technical Research (COST) is a step in this direction [39]. The basic mechanisms involved in the increased cardiovascular risk of obstructive sleep apnoea syndrome remain unclear. In particular, there is a substantial deficit in translational studies that have evaluated specific aspects of this relationship in cell culture or animal models and applied the findings to human populations with obstructive sleep apnoea syndrome. Research in these relationships carries the prospect of identifying novel therapies that should improve the overall health of the population.

The Management Committee of COST Action B26 Obstructive Sleep Apnoea is as follows: W.T. McNicholas (Chair), M.R. Bonsignore (Past-Chair), P. Levy (Vice-Chair), A. Alonderis, F. Barbe Illa, P. Calverley, W. De Backer, K. Diefenbach, V. Donic, I. Fietze, K. Franklin, L. Grote, J. Hedner, P.J. Jennum, L. Lavie, P. Lavie, J. Montserrat, G. Parati, T. Penzel, O. Polo, R. Riha, D. Rodenstein, R. Schulz, E. Sforza, P. Sliwinski, Z. Tomori, G. Varoneckas and J. Zielinski.

\section{REFERENCES}

1 American Academy of Sleep Medicine (AASM). International Classification of Sleep Disorders. Westchester, AASM, 2005.

2 Hosselet JJ, Ayappa I, Norman RG, Krieger AC, Rapoport DM. Classification of sleep-disordered breathing. Am J Respir Crit Care Med 2001; 163: 398-405.

3 Breathing disorders in adults, recommendations for syndrome definition and measurement techniques in clinical research. The report of an American Academy of Sleep Medicine Task Force. Sleep 1999; 22: 667-689.

4 Stradling JR, Davies RJO. Sleep 1. Obstructive sleep apnoea/hypopnoea syndrome: definitions, epidemiology, and natural history. Thorax 2004; 59: 73-78.

5 Teran-Santos J, Jimenez-Gomez A, Cordero-Guevara J. The association between sleep apnoea and the risk of traffic accidents. Cooperative Group Burgos-Santander. N Engl J Med 1999; 340: 847-851.

6 Finn L, Young T, Palta M, Fryback DG. Sleep-disordered breathing and self-reported general health status in the Wisconsin Sleep Cohort Study. Sleep 1998; 21: 701-706.

7 Akashiba T, Kawahara S, Akahoshi T, et al. Relationship between quality of life and mood or depression in 
patients with severe obstructive sleep apnea syndrome. Chest 2002; 122: 861-865.

8 Schwartz DJ, Kohler WC, Karatinos G. Symptoms of depression in individuals with obstructive sleep apnea may be amenable to treatment with continuous positive airway pressure. Chest 2005; 128: 1304-1309.

9 Phillips B. Sleep-disordered breathing and cardiovascular disease. Sleep Med Rev 2005; 9: 131-140.

10 Sullivan CE, Issa F, Berthon-Jones M, Eves L. Reversal of obstructive sleep apnea by continuous positive airway pressure applied by the nares. Lancet 1981; 1: 862-865.

11 Gordon P, Sanders MH. Sleep 7: Positive airway pressure therapy for obstructive sleep apnoea/hypopnoea syndrome. Thorax 2005; 60: 68-75.

12 Giles TL, Lasserson TJ, Smith BJ, White J, Wright J, Cates CJ. Continuous positive airways pressure for obstructive sleep apnoea in adults. Cochrane Database Syst Rev 2006; 3: CD001106.

13 Lim J, Lasserson TJ, Fleetham J, Wright J. Oral appliances for obstructive sleep apnoea. Cochrane Database Syst Rev 2006; 1: CD004435.

14 Sundaram S, Bridgman SA, Lim J, Lasserson TJ. Surgery for obstructive sleep apnoea. Cochrane Database Syst Rev 2005; 4: CD001004.

15 Ryan CF. Sleep 9: An approach to treatment of obstructive sleep apnoea/hypopnoea syndrome including upper airway surgery. Thorax 2005; 60: 595-604.

16 Wittman V, Rodenstein DO. Health care costs and the sleep apnea syndrome. Sleep Med Rev 2004; 8: 269-279.

17 Tarasiuk A, Greenberg-Dotan S, Brin YS, Simon T, Tal A, Reuveni $\mathrm{H}$. Determinants affecting health-care utilization in obstructive sleep apnea syndrome patients. Chest 2005; 128: 1310-1314.

18 Smith R, Ronald J, Dealaive K, Walld R, Manfreda J, Kryger $\mathrm{MH}$. What are obstructive sleep apnea patients being treated for prior to this diagnosis? Chest 2002; 12 : 164-172.

19 Krieger J, Meslier N, Lebrun $\mathrm{T}$, et al. Accidents in obstructive sleep apnea patients treated with nasal continuous positive pressure: a prospective study. Chest 1997; 112: 1561-1566.

20 Ayas NT, Fitzgerald JM, Fleetham JA, et al. Costeffectiveness of continuous positive airway pressure therapy for moderate to severe obstructive sleep apnea/ hypopnea. Arch Intern Med 2006; 166: 977-984.

21 Pelletier-Fleury N, Meslier N, Gagnadoux F, et al. Economic arguments for the immediate management of moderate-to-severe obstructive sleep apnoea syndrome. Eur Respir J 2004; 23: 53-60.

22 Young T, Palta M, Dempsey J, Skatrud J, Weber S, Badr S. The occurrence of sleep-disordered breathing among middle-aged adults. N Engl J Med 1993; 328: 1230-1235.

23 Durán J, Esnaola S, Rubio R, Iztueta A. Obstructive sleep apnea-hypopnea and related clinical features in a population-based sample of subjects aged 30 to $70 \mathrm{yr}$. Am J Respir Crit Care Med 2001; 163: 685-689.

24 Tishler PV, Larkin EK, Schluchter MD, Redline S. Incidence of sleep disordered breathing in an urban adult population: the relative importance of risk factors in the development of sleep-disordered breathing. JAMA 2003; 289: 2230-2237.
25 Ferretti A, Giampiccolo P, Cavalli A, Milic-Emili J, Tantucci C. Expiratory flow limitation and orthopnea in massively obese subjects. Chest 2001; 119: 1401-1408.

26 Newman AB, Foster G, Givelber R, Nieto FJ, Redline S, Young T. Progression and regression of sleep-disordered breathing with changes in weight: the Sleep Heart Health Study. Arch Intern Med 2005; 165: 2408-2413.

27 Young T, Peppard PE, Taheri S. Excess weight and sleepdisordered breathing. J Appl Physiol 2005; 99: 1592-1599.

28 Young T, Peppard PE, Gottlieb DJ. Epidemiology of obstructive sleep apnea. A population health perspective. Am J Respir Crit Care Med 2002; 165: 1217-1239.

29 Villanueva AT, Buchanan PR, Yee BJ, Grunstein RR. Ethnicity and obstructive sleep apnoea. Sleep Med Rev 2005; 9: 419-436.

30 Punjabi NM, Polotsky VY. Disorders of glucose metabolism in sleep apnea. J Appl Physiol 2005; 99: 1998-2007.

31 Vgontzas AN, Bixler EO, Chrousos GP. Sleep apnea is a manifestation of the metabolic syndrome. Sleep Med Rev 2005; 9: 211-224.

32 Bixler EO, Vgontzas AN, Ten Have T, Tyson K, Kales A. Effects of age on sleep apnea in men: I. Prevalence and severity. Am J Respir Crit Care Med 1998; 157: 144-148.

33 Bixler EO, Vgontzas AN, Lin HM, et al. Prevalence of sleep-disordered breathing in women: effects of gender. Am J Respir Crit Care Med 2001; 163: 608-613.

34 Quan SF, Howard BV, Iber C, et al. The Sleep Heart Health Study: design, rationale, and methods. Sleep 1997; 20: 1077-1085.

35 Redline S, Tishler PV, Hans MG, Tosteson TD, Strohl KP, Spry K. Racial differences in sleep-disordered breathing in African-Americans and Caucasians. Am J Respir Crit Care Med 1997; 155: 186-192.

36 Redline S, Tishler PV, Schluchter M, Aylor J, Clark K, Graham G. Risk factors for sleep-disordered breathing in children. Associations with obesity, race, and respiratory problems. Am J Respir Crit Care Med 1999; 159: 1527-1532.

37 Netzer NC, Hoegel JJ, Loube D, et al. Prevalence of symptoms and risk of sleep apnea in primary care. Chest 2003; 124: 1406-1414.

38 Halban PA, Ferrannini E, Nerup J. Diabetes research investment in the European Union. Nature Med 2006; 12: 70-72.

39 European Science Foundation. COST program website. www.cost.esf.org. Date last updated: August 2001.

40 Obstructive sleep apnoea syndrome. Action B26 website: www.costB26.net.

41 Marrone O, Bonsignore MR. Pulmonary haemodynamics in obstructive sleep apnoea. Sleep Med Rev 2002; 6: 175-193.

42 Lugaresi E, Cirignotta F, Coccagna G, Piana C. Some epidemiological data on snoring and cardiocirculatory disturbances. Sleep 1980; 3: 221-224.

43 Partinen M, Guilleminault C. Daytime sleepiness and vascular morbidity at seven-year follow-up in obstructive sleep apnea patients. Chest 1990; 97: 27-32.

44 Pendlebury ST, Pepin JL, Veale D, Levy P. Natural evolution of moderate sleep apnoea syndrome: significant progression over a mean of 17 months. Thorax 1997; 52: $872-878$.

45 Zaninelli A, Fariello R, Boni E, Corda L, Alicandri C, Grassi V. Snoring and risk of cardiovascular disease. Int J Cardiol 1991; 32: 347-351. 
46 Peker Y, Hedner J, Norum J, Kraiczi H, Carlson J. Increased incidence of cardiovascular disease in middleaged men with obstructive sleep apnea: a 7-year followup. Am J Respir Crit Care Med 2002; 166: 159-165.

47 Marin JM, Carrizo SJ, Vicente E, Agusti AG. Long-term cardiovascular outcomes in men with obstructive sleep apnoea-hypopnoea with or without treatment with continuous positive airway pressure: an observational study. Lancet 2005; 365: 1046-1053.

48 Doherty LS, Kiely JL, Swan V, McNicholas WT. Longterm effects of nasal continuous positive airway pressure therapy on cardiovascular outcomes in sleep apnea syndrome. Chest 2005; 127: 2076-2084.

49 Kiely JL, McNicholas WT. Cardiovascular risk factors in patients with obstructive sleep apnoea syndrome. Eur Respir J 2000; 16: 128-133.

50 Coughlin SR, Mawdsley L, Mugarza JA, Calverley PM, Wilding JP. Obstructive sleep apnoea is independently associated with an increased prevalence of metabolic syndrome. Eur Heart J 2004; 25: 735-741.

51 Yaggi HK, Concato J, Kernan WN, Lichtman JH, Brass LM, Mohsenin V. Obstructive sleep apnea as a risk factor for stroke and death. N Engl J Med 2005; 353: 2034-2041.

52 Partinen M, Jamieson A, Guilleminault C. Long-term outcome for obstructive sleep apnea syndrome patients. Mortality. Chest 1988; 94: 1200-1204.

53 He J, Kryger MH, Zorick FJ, Conway W, Roth T. Mortality and apnea index in obstructive sleep apnea. Experience in 385 male patients. Chest 1988; 94: 9-14.

54 Lavie P, Lavie L, Herer P. All-cause mortality in males with sleep apnoea syndrome: declining mortality rates with age. Eur Respir J 2005; 25: 514-520.

55 Veale D, Chailleux E, Hoorelbeke-Ramon A, et al. Mortality of sleep apnoea patients treated by nasal continuous positive airway pressure registered in the ANTADIR observatory. Association Nationale pour le Traitement A Domicile de l'Insuffisance Respiratoire chronique. Eur Respir J 2000; 15: 326-331.

56 Marti S, Sampol G, Munoz X, et al. Mortality in severe sleep apnoea/hypopnoea syndrome patients: impact of treatment. Eur Respir J 2002; 20: 1511-1518.

57 Campos-Rodriguez F, Pena-Grinan N, Reyes-Nunez N, et al. Mortality in obstructive sleep apnea-hypopnea patients treated with positive airway pressure. Chest 2005; 128: 624-633.

58 Seppälä T, Partinen M, Penttila A, Aspholm R, Tiainen E, Kaukianen A. Sudden death and sleeping history among Finnish men. J Intern Med 1991; 229: 23-28.

59 Gami AS, Howard DE, Olson EJ, Somers VK. Day-night pattern of sudden death in obstructive sleep apnea. $N$ Engl J Med 2005; 352: 1206-1214.

60 Robinson GV, Stradling JR, Davies RJ. Sleep. 6: Obstructive sleep apnoea/hypopnoea syndrome and hypertension. Thorax 2004; 59: 1089-1094.

61 Dart RA, Gregoire JR, Gutterman DD, Woolf SH. The association of hypertension and secondary cardiovascular disease with sleep-disordered breathing. Chest 2003; 123: 244-260.

62 Lattimore JL, Celermajer DS, Wilcox I. Obstructive sleep apnea and cardiovascular disease. J Am Coll Cardiol 2003; 41: 429-437.
63 Davies CW, Crosby JH, Mullins RL, Barbour C, Davies RJ, Stradling JR. Case-control study of 24 hour ambulatory blood pressure in patients with obstructive sleep apnoea and normal matched control subjects. Thorax 2000; 55: 736-740

64 Hedner J, Bengtsson-Boström K, Peker Y, Grote L, Råstam L, Lindblad U. Hypertension prevalence in obstructive sleep apnoea and sex: a population-based case-control study. Eur Respir J 2006; 27: 1-7.

65 Hla KM, Young TB, Bidwell T, Palta M, Skatrud JB, Dempsey J. Sleep apnea and hypertension. A populationbased study. Ann Intern Med 1994; 120: 382-388.

66 Young T, Peppard P, Palta M, et al. Population-based study of sleep-disordered breathing as a risk factor for hypertension. Arch Intern Med 1997; 157: 1746-1752.

67 Grote L, Ploch T, Heitmann J, Knaack L, Penzel T, Peter JH. Sleep-related breathing disorder is an independent risk factor for systemic hypertension. Am J Respir Crit Care Med 1999; 160: 1875-1882.

68 Lavie P, Herer P, Hoffstein V. Obstructive sleep apnoea syndrome as a risk factor for hypertension: population study. BMJ 2000; 320: 479-482.

69 Nieto FJ, Young TB, Lind BK, et al. Association of sleepdisordered breathing, sleep apnea, and hypertension in a large community-based study. Sleep Heart Health Study. JAMA 2000; 283: 1829-1836.

70 Logan AG, Perlikowski SM, Mente A, et al. High prevalence of unrecognized sleep apnoea in drugresistant hypertension. J Hypertens 2001; 19: 2271-2277.

71 Peppard PE, Young T, Palta M, Skatrud J. Prospective study of the association between sleep-disordered breathing and hypertension. N Engl J Med 2000; 342: 1378-1384.

72 Wright JT Jr, Redline S, Taylor AL, et al. Relationship between 24-h blood pressure and sleep disordered breathing in a normotensive community sample. Am J Hypertens 2001; 14: 743-748.

73 Faccenda JF, Mackay TW, Boon NA, Douglas NJ. Randomized placebo controlled trial of continuous positive airway pressure on blood pressure in the sleep apnea-hypopnea syndrome. Am J Respir Crit Care Med 2001; 163: 344-348.

74 Pepperell JC, Ramdassingh-Dow S, Crosthwaite N, et al. Ambulatory blood pressure after therapeutic and subtherapeutic nasal continuous positive airway pressure for obstructive sleep apnoea: a randomised parallel trial. Lancet 2002; 359: 204-210.

75 Becker HF, Jerrentrup A, Ploch T, et al. Effect of nasal continuous positive airway pressure treatment on blood pressure in patients with obstructive sleep apnea. Circulation 2003; 107: 68-73.

76 Logan AG, Tkacova R, Perlikowski SM, et al. Refractory hypertension and sleep apnoea: effect of CPAP on blood pressure and baroreflex. Eur Respir J 2003; 21: 241-247.

77 Dhillon S, Chung SA, Fargher T, Huterer N, Shapiro CM. Sleep apnea, hypertension, and the effects of continuous positive airway pressure. Am J Hypertens 2005; 18: 594-600.

78 Brooks D, Horner RL, Kozar LF, Render-Teixeira CL, Phillipson EA. Obstructive sleep apnea as a cause of systemic hypertension. Evidence from a canine model. J Clin Invest 1997; 99: 106-109. 
79 Parker JD, Brooks D, Kozar LF, et al. Acute and chronic effects of airway obstruction on canine left ventricular performance. Am J Respir Crit Care Med 1999; 160: 1888-1896.

80 Fletcher EC. Physiological consequences of intermittent hypoxia: systemic blood pressure. J Appl Physiol 2001; 90: 1600-1605.

81 Norman D, Loredo JS, Nelesen RA, et al. Effects of continuous positive airway pressure versus supplemental oxygen on 24-hour ambulatory blood pressure. Hypertension 2006; 47: 840-845.

82 Baguet JP, Hammer L, Levy P, et al. Night-time and diastolic hypertension are common and underestimated conditions in newly diagnosed apnoeic patients. J Hypertens 2005; 23: 521-527.

83 Baguet J, Narkiewicz K, Mallion J. Update on hypertension management: obstructive sleep apnea and hypertension. J Hypertens 2006; 24: 205-208.

84 Sharabi Y, Scope A, Chorney N, Grotto I, Dagan Y. Diastolic blood pressure is the first to rise in association with early subclinical obstructive sleep apnea: lessons from periodic examination screening. Am J Hypertens 2003; 16: 236-239.

85 Haas DC, Foster GL, Nieto FJ, et al. Age-dependent associations between sleep-disordered breathing and hypertension. Circulation 2005; 111: 614-621.

86 Grote L, Hedner J, Peter JH. Mean blood pressure, pulse pressure and grade of hypertension in untreated hypertensive patients with sleep-related breathing disorders. J Hypertens 2001; 19: 683-690.

87 Sin DD, Fitzgerald F, Parker JD, et al. Relationship of systolic BP to obstructive sleep apnea in patients with heart failure. Chest 2003; 123: 1536-1543.

88 Planes C, Leroy M, Fayet G, Aegerter P, Foucher A, Raffestin B. Exacerbation of sleep-apnoea related nocturnal blood pressure fluctuations in hypertensive subjects. Eur Respir J 2002; 20: 151-157.

89 Bonsignore MR, Parati G, Insalaco G, et al. CPAP treatment improves baroreflex control of heart rate during sleep in severe OSAS. Am J Respir Crit Care Med 2002; 166: 279-286.

90 Kraiczi H, Peker Y, Caidhal K, Samuelsson A, Hedner J. Blood pressure, cardiac structure and severity of obstructive sleep apnea in a sleep clinic population. J Hypertens 2001; 19: 2071-2078.

91 Niroumand M, Kuperstein R, Sasson Z, Hanly PJ. Impact of obstructive sleep apnea on left ventricular mass and diastolic function. Am J Respir Crit Care Med 2001; 163: 1632-1636.

92 Shivalkar B, Van de Heyning C, Kerremans M, et al. Obstructive sleep apnea syndrome: more insights on structural and functional cardiac alterations, and the effects of treatment with continuous positive airway pressure. J Am Coll Cardiol 2006; 47: 1433-1439.

93 Cloward TV, Walker JM, Farney RJ, Anderson JL. Left ventricular hypertrophy is a common echocardiographic abnormality in severe obstructive sleep apnea and reverses with nasal continuous positive airway pressure. Chest 2003; 124: 594-601.

94 Usui K, Parker JD, Newton GE, Floras JS, Ryan CM, Bradley TD. Left ventricular structural adaptations to obstructive sleep apnea in dilated cardiomyopathy. Am J Respir Crit Care Med 2006; 173: 1170-1175.

95 Dursunoglu D, Dursunoglu N, Evrengul H, et al. Impact of obstructive sleep apnoea on left ventricular mass and global function. Eur Respir J 2005; 26: 283-288.

96 Arias MA, Garcia-Rio F, Alonso-Fernadez A, Mediano O, Martinez I, Villamor J. Obstructive sleep apnea syndrome affects left ventricular diastolic function: effects of nasal continuous positive airway pressure in men. Circulation 2005; 112: 375-383.

97 Fung JW, Li TS, Choy DK, et al. Severe obstructive sleep apnea is associated with left ventricular diastolic dysfunction. Chest 2002; 121: 422-429.

98 Marcus CL, Greene MG, Carroll JL. Blood pressure in children with obstructive sleep apnea. Am J Respir Crit Care Med 1998; 157: 1098-1103.

99 Kohyama J, Ohinata JS, Hasegawa T. Blood pressure in sleep disordered breathing. Arch Dis Child 2003; 88: 139-142.

100 Enright PL, Goodwin JL, Sherrill DL, Quan JR, Quan SF, Tucson Children's Assessment of Sleep Apnea study. Blood pressure elevation associated with sleep-related breathing disorder in a community sample of white and Hispanic children: the Tucson Children's Assessment of Sleep Apnea study. Arch Pediatr Adolesc Med 2003; 157: 901-904.

101 Amin RS, Carroll JL, Jeffries JL, et al. Twenty-four-hour ambulatory blood pressure in children with sleepdisordered breathing. Am J Respir Crit Care Med 2004; 169: 950-956.

102 Amin RS, Kimball TR, Bean JA, et al. Left ventricular hypertrophy and abnormal ventricular geometry in children and adolescents with obstructive sleep apnea. Am J Respir Crit Care Med 2002; 165: 1395-1399.

103 Amin RS, Kimball TR, Kalra M, et al. Left ventricular function in children with sleep-disordered breathing. Am J Cardiol 2005; 95: 801-804.

104 O'Brien LM, Gozal D. Autonomic dysfunction in children with sleep-disordered breathing. Sleep 2005; 28: 747-752.

105 Tam CS, Wong M, Mcbain R, Bailey S, Waters KA. Inflammatory measures in children with obstructive sleep apnoea. J Paediatr Child Health 2006; 42: 277-282.

106 O'Brien LM, Serpero LD, Tauman R, Gozal D. Plasma adhesion molecules in children with sleep-disordered breathing. Chest 2006; 129: 947-953.

107 Larkin EK, Rosen CL, Kirchner HL, et al. Variation of Creactive protein levels in adolescents: association with sleep-disordered breathing and sleep duration. Circulation 2005; 111: 1978-1984.

108 Ng DK, Chan C, Chow AS, Chow P, Kwok K. Childhood sleep-disordered breathing and its implications for cardiac and vascular diseases. I Paediatr Child Health 2005; 41: 640-646.

109 Kelly A, Marcus CL. Childhood obesity, inflammation, and apnea. What is the future for our children? Am J Respir Crit Care Med 2005; 171: 202-203.

110 Peker Y, Kraiczi H, Hedner J, Loth S, Johansson A, Bende M. An independent association between obstructive sleep apnoea and coronary artery disease. Eur Respir J 1999; 14: 179-184. 
111 Mooe T, Rabben T, Wiklund U, Franklin KA, Eriksson P. Sleep-disordered breathing in men with coronary artery disease. Chest 1996; 109: 659-663.

112 Mooe T, Rabben T, Wiklund U, Franklin KA, Eriksson P. Sleep-disordered breathing in women: occurrence and association with coronary artery disease. Am J Med 1996; 101: 251-256.

113 Shahar E, Whitney CW, Redline S, et al. Sleep-disordered breathing and cardiovascular disease. Cross-sectional results of the Sleep Heart Health Study. Am J Respir Crit Care Med 2001; 163: 19-25.

114 Hedner J, Franklin K, Peker Y. Obstructive sleep apnea and coronary artery disease. In: Kryger MH, Roth T, Dement WC, eds. Principles and Practice of Sleep Medicine. 4th Edn. Philadelphia, Elsevier, 2005; pp. 1203-1207.

115 Bonsignore MR, Smirne S, Marrone O, Insalaco G, Salvaggio A, Bonsignore G. Myocardial ischemia during sleep. Sleep Med Rev 1999; 3: 241-255.

116 Peker Y, Hedner J, Kraiczi H, Löth S. Respiratory disturbance index. An independent predictor of mortality in coronary artery disease. Am J Respir Crit Care Med 2000; 162: 81-86.

117 Mooe T, Franklin KA, Holmstrom K, Rabben T, Wiklund U. Sleep disordered breathing and coronary artery disease: long-term prognosis. Am J Respir Crit Care Med 2001; 164: 1910-1913.

118 Milleron O, Pilliere $\mathrm{R}$, Foucher A, et al. Benefits of obstructive sleep apnoea treatment in coronary artery disease: a long-term follow-up study. Eur Heart J 2004; 25: 728-734.

119 Peker Y, Carlson J, Hedner J. Increased incidence of coronary artery disease in sleep apnoea: a long-term follow-up. Eur Respir J 2006; 28: 596-602.

120 Hayashi M, Fujimoto K, Urushibata K, Uchikawa S, Imamura $\mathrm{H}$, Kubo K. Nocturnal oxygen desaturation correlates with the severity of coronary atherosclerosis in coronary artery disease. Chest 2003; 124: 936-941.

121 Hagenah GC, Gueven E, Andreas S. Influence of obstructive sleep apnoea in coronary artery disease: a 10-year follow-up. Respir Med 2006; 100: 180-182.

122 Philip P, Guilleminault C. ST segment abnormality, angina during sleep and obstructive sleep apnea. Sleep 1993; 16: 558-559.

123 Gami AS, Svatikova A, Wolk R, et al. Cardiac troponin T in obstructive sleep apnea. Chest 2004; 125: 2097-2100.

124 Joyeux-Faure M, Stanke-Labesque F, Lefebvre B, et al. Chronic intermittent hypoxia increases infarction in the isolated rat heart. J Appl Physiol 2005; 98: 1691-1696.

125 Béguin PC, Joyeux-Faure M, Godin-Ribuot D, Lévy P, Ribuot C. Acute intermittent hypoxia improves rat myocardium tolerance to ischemia. J Appl Physiol 2005; 99: 1064-1069.

126 Hanly P, Sasson Z, Zuberi N, Lunn K. ST-segment depression during sleep in obstructive sleep apnea. Am J Cardiol 1993; 71: 1341-1345.

127 Schäfer H, Koehler U, Ploch T, Peter JH. Sleep-related myocardial ischemia and sleep structure in patients with obstructive sleep apnea and coronary heart disease. Chest 1997; 111: 387-393.

128 Peled N, Abinader EG, Pillar G, Sharif D, Lavie P. Nocturnal ischemic events in patients with obstructive sleep apnea syndrome and ischemic heart disease: effects of continuous positive air pressure treatment. J Am Coll Cardiol 1999; 34: 1744-1749.

129 Alonso-Fernandez A, Garcia-Rio F, Racionero MA, et al. Cardiac rhythm disturbances and ST-segment depression episodes in patients with obstructive sleep-apnea-hypopnea syndrome and its mechanisms. Chest 2005; 127: 15-22.

130 Mooe T, Franklin KA, Wiklund U, Rabben T, Holmström K. Sleep-disordered breathing and myocardial ischemia in patients with coronary artery disease. Chest 2000; 117: 1597-1602.

131 Mutlu GM, Rubinstein I. Obstructive sleep apnea syndrome-associated nocturnal myocardial ischemia. Chest 2000; 117: 1534-1535.

132 Peters RW. Obstructive sleep apnea and cardiovascular disease. Chest 2005; 127: 1-3.

133 Yaggi $H$, Mohsenin V. Obstructive sleep apnoea and stroke. Lancet Neurol 2004; 3: 333-342.

134 Turkington PM, Elliott MW. Sleep disordered breathing following stroke. Monaldi Arch Chest Dis 2004; 61: 157-161.

135 Grigg-Damberger M. Why a polysomnogram should become part of the diagnostic evaluation of stroke and transient ischemic attack. J Clin Neurophysiol 2006; 23:21-38.

136 Brown DL, Chervin RD, Hickenbottom SL, Langa KM, Morgenstern LB. Screening for obstructive sleep apnea in stroke patients. A cost-effectiveness analysis. Stroke 2005 36: 1291-1293.

137 Williams LS, Holloway RG. How much is a good night's sleep worth? Stroke 2005; 36; 1293-1294.

138 Arzt M, Young T, Finn L, Skatrud JB, Bradley TD. Association of sleep disordered breathing and the occurrence of stroke. Am J Respir Crit Care Med 2005; 172: 1447-1451.

139 Elwood P, Hack M, Pickering J, Hughes J, Gallacher J. Sleep disturbance, stroke, and heart disease events: evidence from the Caerphilly cohort. I Epidemiol Community Health 2006; 60: 69-73.

140 Gibson GJ. Sleep disordered breathing and the outcome of stroke. Thorax 2004; 59: 361-363.

141 Baguet JP, Hammer L, Levy P, et al. The severity of oxygen desaturation is predictive of carotid wall thickening and plaque occurrence. Chest 2005; 128: 3407-3412.

142 Suzuki T, Nakano H, Maekawa J, et al. Obstructive sleep apnea and carotid-artery intima-media thickness. Sleep 2004; 27: 129-133.

143 Parra O, Arboix A, Bechich S, et al. Time course of sleep-related breathing disorders in first-ever stroke or transient ischemic attack. Am J Respir Crit Care Med 2000; 161: 375-380.

144 Bassetti C, Aldrich MS, Chervin RD, Quint D. Sleep apnea in patients with transient ischemic attack and stroke: a prospective study of 59 patients. Neurology 1996; 47: 1167-1173.

145 McArdle N, Riha RL, Vennelle M, et al. Sleep-disordered breathing as a risk factor for cerebrovascular disease. A case-control study in patients with transient ischemic attacks. Stroke 2003; 34: 2916-2921.

146 Selic C, Siccoli MM, Hermann DM, Bassetti CL. Blood pressure evolution after acute ischemic stroke in patients with and without sleep apnea. Stroke 2005; 36: 2614-2618. 
147 Parra O, Arboix A, Montserrat JM, Quinto L, Bechich S, Garcia-Eroles L. Sleep-related breathing disorders: impact on mortality of cerebrovascular disease. Eur Respir J 2004; 24: 267-272.

148 Martinez-Garcia MA, Galiano-Blancart R, RomanSanchez P, Soler-Cataluna JJ, Cabero-Salt L, SalcedoMaiques E. Continuous positive airway pressure treatment in sleep apnea prevents new vascular events after ischemic stroke. Chest 2005; 128: 2123-2129.

149 Dziewas R, Humpert M, Hopmann B, et al. Increased prevalence of sleep apnea in patients with recurring ischemic stroke compared with first stroke victims. J Neurol 2005; 252: 1394-1398.

150 Kaneko Y, Hajek VE, Zivanovic V, Raboud J, Bradley TD. Relationship of sleep apnea to functional capacity and length of hospitalization following stroke. Sleep 2003; 26: 293-297.

151 Bassetti CL, Milanova M, Gugger M. Sleep-disordered breathing and acute ischemic stroke. Diagnosis, risk factors, treatment, evolution, and long-term clinical outcome. Stroke 2006; 37: 967-972.

152 Davies CWH, Crosby JH, Mullins RL, et al. Case control study of cerebrovascular damage defined by magnetic resonance imaging in patients with OSA and normal matched control subjects. Sleep 2001; 24: 715-720.

153 Harbison J, Gibson GJ, Birchall D, Zammit-Maempel I, Ford GA. White matter disease and sleep-disordered breathing after acute stroke. Neurology 2003; 61: 959-963.

154 Ding J, Nieto FJ, Beauchamp NJ Jr. et al. Sleep-disordered breathing and white matter disease in the brainstem in older adults. Sleep 2004; 27: 474-479.

155 Alchanatis M, Deligiorgis N, Zias N, et al. Frontal brain lobe impairment in obstructive sleep apnoea: a proton MR spectroscopy study. Eur Respir J 2004; 24: 980-986.

156 Dyken ME, Yamada T, Glenn CL, Berger HA. Obstructive sleep apnea associated with cerebral hypoxemia and death. Neurology 2004; 62: 491-493.

157 Pinski MR. Sleeping with the enemy: the heart in obstructive sleep apnea. Chest 2002; 121: 1022-1024.

158 Bradley TD, Floras, Sleep apnea and heart failure. Part I: obstructive sleep apnea. Circulation 2003; 107: 1671-1678.

159 Naughton MT. Heart failure and obstructive apnoea. Sleep Med Rev 1998; 2: 93-103.

160 Caples SM, Wolk R, Somers VK. Influence of cardiac function and failure on sleep-disordered breathing: evidence for a causative role. J Appl Physiol 2005; 99: 2433-2439.

161 Arzt M, Bradley TD. Treatment of sleep apnea in heart failure. Am J Respir Crit Care Med 2006; 173: 1300-1308.

162 Javaheri S, Parker TJ, Liming JD, et al. Sleep apnea in 81 ambulatory male patients with stable heart failure: types and their prevalences, consequences, and presentations. Circulation 1998; 97: 2154-2159.

163 Sin DD, Fitzgerald F, Parker JD, Newton G, Floras JS, Bradley TD. Risk factors for central and obstructive sleep apnea in 450 men and women with congestive heart failure. Am J Respir Crit Care Med 1999; 160: 1101-1106.

164 Ferrier K, Campbell, Yee B, et al. Sleep-disordered breathing occurs frequently in stable outpatients with congestive heart failure. Chest 2005; 128: 2116-2122.
165 Javaheri S. Sleep disorders in systolic heart failure: a prospective study of 100 male patients. The final report. Int J Cardiol 2006; 106: 21-28.

166 Parker JD, Brooks D, Kozar LF, et al. Acute and chronic effects of airway obstruction on canine left ventricular performance. Am J Respir Crit Care Med 1999; 160: 1888-1896.

167 Hall MJ, Ando SI, Floras JS, Bradley TD. Magnitude and time course of hemodynamic responses to Mueller maneuvers in patients with congestive heart failure. J Appl Physiol 1998; 85: 1476-1484.

168 Tkacova R, Rankin F, Fitzgerald FS, Floras JS, Bradley TD. Effects of continuous positive airway pressure on obstructive sleep apnea and left ventricular afterload in patients with heart failure. Circulation 1998; 98: 2269-2275.

169 Laaban J-P, Pascal-Sebaoun S, Bloch E, Orvoen-Frija E, Oppert J-M, Huchon G. Left ventricular systolic dysfunction in patients with obstructive sleep apnea syndrome. Chest 2002; 122: 1133-1138.

170 Kaneko Y, Floras JS, Usui K, et al. Cardiovascular effects of continuous positive airway pressure in patients with heart failure and obstructive sleep apneas. $N$ Engl J Med 2003; 348: 1233-1241.

171 Mansfield DR, Gollogly NC, Kaye DM, Richardson M, Bergin P, Naughton MT. Controlled trial of continuous positive airway pressure in obstructive sleep apnea and heart failure. Am I Respir Crit Care Med 2004; 169: 361-366.

172 Malone S, Liu PP, Holloway R, Rutherford R, Xie A, Bradley TD. Obstructive sleep apnoea in patients with dilated cardiomyopathy: effects of continuous positive airway pressure. Lancet 1991; 338: 1480-1484.

173 Roebuck T, Solin P, Kaye DM, Bergin P, Bailey M, Naughton MT. Increased long-term mortality in heart failure due to sleep apnoea is not yet proven. Eur Respir J 2004; 23: 735-740.

174 Ancoli-Israel S, DuHamel ER, Stepnowsky C, Engler R, Cohen-Zion $\mathrm{M}$, Marler $\mathrm{M}$. The relationship between congestive heart failure, sleep apnea, and mortality in older men. Chest 2003; 124: 1400-1405.

175 Spaak J, Egri ZJ, Kubo T, et al. Muscle sympathetic nerve activity during wakefulness in heart failure patients with and without sleep apnea. Hypertension 2005; 46: 1327-1332.

176 Usui K, Bradley TD, Spaak J, et al. Inhibition of awake sympathetic nerve activity of heart failure patients with obstructive sleep apnoea by nocturnal continuous positive airway pressure. J Am Coll Cardiol 2005; 45: 2008-2011.

177 Mansfield D, Kaye DM, Brunner La Rocca H, Solin P, Esler MD, Naughton MT. Raised sympathetic nerve activity in heart failure and central sleep apnea is due to heart failure severity. Circulation 2003; 107: 1396-1400.

178 Shamsuzzaman AS, Gersh BJ, Somers VK. Obstructive sleep apnea. Implications for cardiac and vascular disease. JAMA 2003; 290: 1906-1914.

179 Adlakha A, Shepard JW Jr. Cardiac arrhythmias during normal sleep and in obstructive sleep apnea syndrome. Clin Chest Med 1992; 13: 437-458.

180 Becker HF, Koehler U, Stammnitz A, Peter JH. Heart block in patients with sleep apnoea. Thorax 1998; 53: Suppl. 3, S29-S32. 
181 Grimm W, Becker HF. Obesity, sleep apnea syndrome, and rhythmogenic risk. Herz 2006; 31: 213-218.

182 Guilleminault C, Connolly SJ, Winkle RA. Cardiac arrhythmia and conduction disturbances during sleep in 400 patients with sleep apnoea syndrome. Am J Cardiol 1983; 52: 490-494.

183 Koehler U, Becker HF, Grimm W, Heitmann J, Peter JH, Schafer H. Relations among hypoxemia, sleep stage, and bradyarrhythmia during obstructive sleep apnoea. Am Heart J 2000; 139: 142-148.

184 Koehler U, Fus E, Grimm W, et al. Heart block in patients with obstructive sleep apnoea: pathogenetic factors and effects of treatment. Eur Respir J 1998; 11: 434-439.

185 Simantirakis EN, Schiza SI, Marketou ME, et al. Severe bradyarrhythmias in patients with sleep apnoea: the effect of continuous positive airway pressure treatment. Eur Heart J 2004; 25: 1070-1076.

186 Flemons WW, Remmers JE, Gillis AM. Sleep apnea and cardiac arrhythmias: is there a relationship? Am Rev Respir Dis 1993; 148: 618-621.

187 Harbison J, O'Reilly P, McNicholas WT. Cardiac rhythm disturbances in the obstructive sleep apnea syndrome: effects of nasal continuous positive airway pressure. Chest 2000; 118: 591-595.

188 Stegman SS, Burroughs JM, Henthorn RW. Asymptomatic bradyarrhythmias as a marker for sleep apnea: appropriate recognition and treatment may reduce the need for pacemaker therapy. Pacing Clin Electrophysiol 1996; 19: 899-904.

189 Fietze I, Rotting J, Quispe-Bravo S, et al. Sleep apnea syndrome in patients with cardiac pacemaker. Respiration 2000; 67: 268-271.

190 Mehra R, Benjamin EJ, Shahar E, et al. Association of nocturnal arrhythmias with sleep-disordered breathing: the Sleep Heart Health Study. Am J Respir Crit Care Med 2006; 173: 910-916.

191 Ryan CM, Usui K, Floras JS, Bradley TD. Effect of continuous positive airway pressure on ventricular ectopy in heart failure patients with obstructive sleep apnoea. Thorax 2005; 60: 781-785.

192 Gami AS, Pressman G, Caples SM, et al. Association of atrial fibrillation and obstructive sleep apnea. Circulation 2004; 110: 364-367.

193 Mooe T, Gullsby S, Rabben T, Eriksson P. Sleep-disordered breathing: a novel predictor of atrial fibrillation after coronary artery bypass surgery. Coron Artery Dis 1996; 7: 475-478.

194 Porthan KM, Melin JH, Kupila JT, Venho KK, Partinen MM. Prevalence of sleep apnea syndrome in lone atrial fibrillation: a case-control study. Chest 2004; 125: 879-885.

195 Schulz R, Eisele HJ, Seeger W. Nocturnal atrial fibrillation in a patient with obstructive sleep apnoea. Thorax 2005; 60: 174

196 Bridgman JC, Heddle WF. Severe nocturnal bradycardia with daytime tachycardia in obstructive sleep apnoea. Med J Aust 2006; 184: 93-94.

197 Kanagala R, Murali NS, Friedman PA, et al. Obstructive sleep apnea and the recurrence of atrial fibrillation. Circulation 2003; 107: 2589-2594.
198 Garrigue S, Bordier $\mathrm{P}$, Jais $\mathrm{P}$, et al. Benefit of atrial pacing in sleep apnea syndrome. N Engl J Med 2002; 346: 404412.

199 Krahn AD, Yee R, Erickson MK, et al. Physiologic pacing in patients with obstructive sleep apnea: a prospective, randomized crossover trial. J Am Coll Cardiol 2006; 47: 379-383.

200 Pepin JL, Defaye P, Garrigue S, Poezevara Y, Levy P. Overdrive atrial pacing does not improve obstructive sleep apnoea syndrome. Eur Respir J 2005; 25: 343-347.

201 Simantirakis EN, Schiza SE, Chrysostomakis SI, et al. Atrial overdrive pacing for the obstructive sleep apneahypopnea syndrome. N Engl J Med 2005; 353: 2568-2577.

202 Unterberg C, Luthje L, Szych J, Vollmann D, Hasenfuss G, Andreas S. Atrial overdrive pacing compared to CPAP in patients with obstructive sleep apnoea syndrome. Eur Heart J 2005; 26: 2568-2575.

203 Luthje L, Unterberg-Buchwald C, Dajani D, Vollmann D, Hasenfuss G, Andreas S. Atrial overdrive pacing in patients with sleep apnea with implanted pacemaker. Am J Respir Crit Care Med 2005; 172: 118-122.

204 Floras JS, Bradley TD. Atrial overdrive pacing for sleep apnea. A door now closed? Am J Respir Crit Care Med 2005; 172: 1-3.

205 Caples SM, Wolk R, Somers VK. Influence of cardiac function and failure on sleep-disordered breathing: evidence for a causative role. J Appl Physiol 2005; 99: 2433-2439.

206 Spiegel K, Knutson K, Leproult R, Tasali E, Van Cauter E. Sleep loss: a novel risk factor for insulin resistance and type 2 diabetes. J Appl Physiol 2005; 99: 2008-2019.

207 Vgontzas AN, Bixler EO, Chrousos GP. Metabolic disturbances in obesity versus sleep apnoea: the importance of visceral obesity and insulin resistance. J Intern Med 2003; 254: 32-44.

208 Harsch IA, Hahn EG, Konturek PC. Insulin resistance and other metabolic aspects of the obstructive sleep apnea syndrome. Med Sci Monit 2005; 11: RA70-RA75.

209 Svatikova A, Wolk R, Gami AS, Pohanka M, Somers VK. Interactions between obstructive sleep apnea and the metabolic syndrome. Curr Diab Rep 2005; 5: 53-58.

210 Punjabi NM, Ahmed MM, Polotsky VY, Beamer BA, O’Donnell CP. Sleep-disordered breathing, glucose intolerance, and insulin resistance. Respir Physiol Neurobiol 2003; 136: 167-178.

211 Ip MS, Lam B, Ng MM, Lam WK, Tsang KW, Lam KS. Obstructive sleep apnea is independently associated with insulin resistance. Am J Respir Crit Care Med 2002; 165: 670-676.

212 Punjabi NM, Sorkin JD, Katzel LI, Goldberg AP, Schwartz AR, Smith PL. Sleep-disordered breathing and insulin resistance in middle-aged and overweight men. Am J Respir Crit Care Med 2002; 165: 677-682.

213 Punjabi NM, Shahar E, Redline S, Gottlieb DJ, Givelber R, Resnick HE. Sleep-disordered breathing, glucose intolerance, and insulin resistance: the Sleep Heart Health Study. Am J Epidemiol 2004; 160: 521-530.

214 Reichmuth KJ, Austin D, Skatrud JB, Young T. Association of sleep apnea and type II diabetes: a population-based study. Am J Respir Crit Care Med 2005; 172: 1590-1595. 
215 Shin C, Kim J, Kim J, et al. Association of habitual snoring with glucose and insulin metabolism in nonobese Korean adult men. Am J Respir Crit Care Med 2005; 171: 287-291.

216 Udwadia ZF, Doshi AV, Lonkar SG, Singh CI. Prevalence of sleep-disordered breathing and sleep apnea in middleaged urban Indian men. Am J Respir Crit Care Med 2004; 169: 168-173.

217 Tassone F, Lanfranco F, Gianotti L, et al. Obstructive sleep apnoea syndrome impairs insulin sensitivity independently of anthropometric variables. Clin Endocrinol 2003; 59: 374-379.

218 Meslier N, Gagnadoux F, Giraud P, et al. Impaired glucose-insulin metabolism in males with obstructive sleep apnoea syndrome. Eur Respir J 2003; 22: 156-160.

219 Makino S, Handa H, Suzukawa K, et al. Obstructive sleep apnoea syndrome, plasma adiponectin levels, and insulin resistance. Clin Endocrinol 2006; 64: 12-19.

220 de la Eva RC, Baur LA, Donaghue KC, Waters KA. Metabolic correlates with obstructive sleep apnea in obese subjects. J Pediatr 2002; 140: 654-659.

221 Tauman R, O'Brien LM, Ivanenko A, Gozal D. Obesity rather than severity of sleep-disordered breathing as the major determinant of insulin resistance and altered lipidemia in snoring children. Pediatrics 2005; 116: e66-e3.

222 Kaditis AG, Alexopoulos EI, Damani E, et al. Obstructive sleep-disordered breathing and fasting insulin levels in nonobese children. Pediatr Pulmonol 2005; 40: 515-523.

223 Oltmanns KM, Gehring H, Rudolf S, et al. Hypoxia causes glucose intolerance in humans. Am J Respir Crit Care Med 2004; 169: 1231-1237.

224 Harsch IA, Schahin SP, Radespiel-Troger M, et al. Continuous positive airway pressure treatment rapidly improves insulin sensitivity in patients with obstructive sleep apnea syndrome. Am J Respir Crit Care Med 2004; 169: 156-162.

225 Czupryniak L, Loba J, Pawlowski M, Nowak D, Bialasiewicz P. Treatment with continuous positive airway pressure may affect blood glucose levels in nondiabetic patients with obstructive sleep apnea syndrome. Sleep 2005; 28: 601-603.

226 Strohl KP. Diabetes and sleep apnea. Sleep 1996; 19: Suppl. 10, S225-S228.

227 Katsumata K, Okada T, Miyao M, Katsumata Y. High incidence of sleep apnea syndrome in a male diabetic population. Diabetes Res Clin Pract 1991; 13: 45-51.

228 Renko AK, Hiltunen L, Laakso M, Rajala U, KeinanenKiukaanniemi S. The relationship of glucose tolerance to sleep disorders and daytime sleepiness. Diabetes Res Clin Pract 2005; 67: 84-91.

229 Bixler EO, Vgontzas AN, Lin HM, Calhoun SL, VelaBueno A, Kales A. Excessive daytime sleepiness in a general population sample: the role of sleep apnea, age, obesity, diabetes, and depression. J Clin Endocrinol Metab 2005; 90: 4510-4515.

230 Enright PL, Newman AB, Wahl PW, Manolio TA, Haponik EF, Boyle PJ. Prevalence and correlates of snoring and observed apneas in 5,201 older adults. Sleep 1996; 19: 531-538.

231 Al-Delaimy WK, Manson JE, Willett WC, Stampfer MJ, $\mathrm{Hu}$ FB. Snoring as a risk factor for type II diabetes mellitus: a prospective study. Am J Epidemiol 2002; 155: 387-393.

232 Chasens ER, Umlauf MG, Pillion DJ, Singh KP. Sleep apnea symptoms, nocturia, and diabetes in AfricanAmerican community dwelling older adults. I Natl Black Nurses Assoc 2000; 11: 25-33.

233 Elmasry A, Janson C, Lindberg E, Gislason T, Tageldin MA, Boman G. The role of habitual snoring and obesity in the development of diabetes: a 10-year follow-up study in a male population. Intern Med 2000; 248: 13-20.

234 Al-Delaimy WK, Manson JE, Willett WC, Stampfer MJ, $\mathrm{Hu}$ FB. Snoring as a risk factor for type II diabetes mellitus: a prospective study. Am J Epidemiol 2002; 155: 387-393.

235 Brooks B, Cistulli PA, Borkman M, et al. Obstructive sleep apnea in obese noninsulin-dependent diabetic patients: effect of continuous positive airway pressure treatment on insulin responsiveness. J Clin Endocrinol Metab 1994; 79: 1681-1685.

236 Babu AR, Herdegen J, Fogelfeld L, Shott S, Mazzone T. Type 2 diabetes, glycemic control, and continuous positive airway pressure in obstructive sleep apnea. Arch Intern Med 2005; 165: 447-452.

237 Hassaballa HA, Tulaimat A, Herdegen JJ, Mokhlesi B. The effect of continuous positive airway pressure on glucose control in diabetic patients with severe obstructive sleep apnea. Sleep Breath 2005; 9: 176-180.

238 Harsch IA, Schahin SP, Bruckner K, et al. The effect of continuous positive airway pressure treatment on insulin sensitivity in patients with obstructive sleep apnoea syndrome and type 2 diabetes. Respiration 2004; 71: 252-259.

239 Villa MP, Multari G, Montesano M, et al. Sleep apnoea in children with diabetes mellitus: effect of glycaemic control. Diabetologia 2000; 43: 696-702.

240 Ficker JH, Dertinger SH, Siegfried W, et al. Obstructive sleep apnoea and diabetes mellitus: the role of cardiovascular autonomic neuropathy. Eur Respir J 1998; 11: 14-19.

241 Mondini S, Guilleminault C. Abnormal breathing patterns during sleep in diabetes. Ann Neurol 1985; 17: 391-395.

242 Bottini P, Dottorini ML, Cristina Cordoni M, Casucci G, Tantucci C. Sleep-disordered breathing in nonobese diabetic subjects with autonomic neuropathy. Eur Respir J 2003; 22: 654-660.

243 Bottini P, Tantucci C. Sleep apnea syndrome in endocrine diseases. Respiration 2003; 70: 320-327.

244 Resnick HE, Redline S, Shahar E, et al. Diabetes and sleep disturbances: findings from the Sleep Heart Health Study. Diabetes Care 2003; 26: 702-709.

245 Robinson GV, Pepperell JC, Segal HC, Davies RJ, Stradling JR. Circulating cardiovascular risk factors in obstructive sleep apnoea: data from randomised controlled trials. Thorax 2004; 59: 777-782.

246 Tan KC, Chow WS, Lam JC, et al. HDL dysfunction in obstructive sleep apnea. Atherosclerosis 2006; 184: 377382.

247 Borgel J, Sanner BM, Bittlinsky A, et al. Obstructive sleep apnoea and its therapy influence high-density lipoprotein cholesterol serum levels. Eur Respir J 2006; 27: 121-127. 
248 Agarwal N, Sharma BC. Insulin resistance and clinical aspects of non-alcoholic steatohepatitis (NASH). Hepatol Res 2005; 33: 92-96.

249 Singh H, Pollock R, Uhanova J, Kryger M, Hawkins K, Minuk GY. Symptoms of obstructive sleep apnea in patients with nonalcoholic fatty liver disease. Dig Dis Sci 2005; 50: 2338-2343.

250 Tanne F, Gagnadoux F, Chazouilleres O, et al. Chronic liver injury during obstructive sleep apnea. Hepatology 2005; 41: 1290-1296.

251 Chin K, Nakamura T, Takahashi K, et al. Effects of obstructive sleep apnea syndrome on serum aminotransferase levels in obese patients. Am J Med 2003; 114: 370-376.

252 Li J, Thorne LN, Punjabi NM, et al. Intermittent hypoxia induces hyperlipidemia in lean mice. Circ Res 2005; 97: 698-706.

253 Li J, Grigoryev DN, Ye SQ, et al. Chronic intermittent hypoxia upregulates genes of lipid biosynthesis in obese mice. J Appl Physiol 2005; 99: 1643-1648.

254 Barcelò A, Miralles C, Barbé F, Vila M, Pons S, Agustì AGN. Abnormal lipid peroxidation in patients with sleep apnoea. Eur Respir J 2000; 16: 644-647.

255 Saarelainen S, Lehtimaki T, Jaakkola $\mathrm{O}$, et al. Autoantibodies against oxidised low-density lipoprotein in patients with obstructive sleep apnoea. Clin Chem Lab Med 1999; 37: 517-520.

256 Fletcher EC, Miller J, Schaaf JW, Fletcher JG. Urinary catecholamines before and after tracheostomy in patients with obstructive sleep apnea and hypertension. Sleep 1987; 10: 35-44.

257 Smith ML, Niedermaier ON, Hardy SM, Decker MJ, Strohl KP. Role of hypoxemia in sleep apnea-induced sympathoexcitation. J Auton Nerv Syst 1996; 56: 184-190.

258 Leuenberger U, Jacob E, Sweer L, Waravdekar N, Zwillich C, Sinoway L. Surges of muscle sympathetic nerve activity during obstructive apnea are linked to hypoxemia. J Appl Physiol 1995; 79: 581-588.

259 Narkiewicz K, van de Borne PJ, Cooley RL, Dyken ME, Somers VK. Sympathetic activity in obese subjects with and without obstructive sleep apnea. Circulation 1998; 98: 772-776.

260 Narkiewicz K, van de Borne PJ, Pesek CA, Dyken ME, Montano N, Somers VK. Selective potentiation of peripheral chemoreflex sensitivity in obstructive sleep apnea. Circulation 1999; 99: 1183-1189.

261 Hedner J, Darpo B, Ejnell H, Carlson J, Caidahl K. Reduction in sympathetic activity after long-term CPAP treatment in sleep apnoea: cardiovascular implications. Eur Respir J 1995; 8: 222-229.

262 Ziegler MG, Mills PJ, Loredo JS, Ancoli-Israel S, Dimsdale JE. Effect of continuous positive airway pressure and placebo treatment on sympathetic nervous activity in patients with obstructive sleep apnea. Chest 2001; 120: 887-893.

263 Heitmann J, Ehlenz K, Penzel T, et al. Sympathetic activity is reduced by $\mathrm{nCPAP}$ in hypertensive obstructive sleep apnoea patients. Eur Respir J 2004; 23: 255-262.

264 Hedner J, Ejnell H, Sellgren J, Hedner T, Wallin G. Is high and fluctuating muscle nerve sympathetic activity in the sleep apnoea syndrome of pathogenetic importance for the development of hypertension? J Hypertens Suppl 1988 6: S529-S531.

265 Somers VK, Dyken ME, Clary MP, Abboud FM. Sympathetic neural mechanisms in obstructive sleep apnea. J Clin Invest 1995; 96: 1897-1904.

266 Carlson JT, Hedner J, Elam M, Ejnell H, Sellgren J, Wallin BG. Augmented resting sympathetic activity in awake patients with obstructive sleep apnea. Chest 1993; 103: 1763-1768.

267 Narkiewicz K, Kato M, Phillips BG, Pesek CA, Davison DE, Somers VK. Nocturnal continuous positive airway pressure decreases daytime sympathetic traffic in obstructive sleep apnea. Circulation 1999; 100: 2332-2335.

268 Parati G, Di Rienzo M, Bertinieri G, et al. Evaluation of the baroreceptor-heart rate reflex by 24 -hour intra-arterial blood pressure monitoring in humans. Hypertension 1988; 12: 214-222.

269 Bertinieri G, Di Rienzo M, Cavallazzi A, Ferrari AU, Pedotti A, Mancia G. Evaluation of baroreceptors reflex by blood pressure monitoring in unanesthetized cats. Am J Physiol 1988; 254: H377-H383.

270 Parati G, Di Rienzo M, Bonsignore MR, et al. Autonomic cardiac regulation in obstructive sleep apnea syndrome: evidence from spontaneous baroreflex analysis during sleep. J Hypertens 1997; 15: 1621-1626.

271 Bonsignore MR, Parati G, Insalaco G, et al. Baroreflex control of heart rate during sleep in severe obstructive sleep apnoea: effects of acute CPAP. Eur Respir J 2006; 27: 128-135.

272 Fletcher EC, Bao G, Li R. Renin activity and blood pressure in response to chronic episodic hypoxia. Hypertension 1999; 34: 309-314.

273 Bao G, Metreveli N, Li R, Taylor A, Fletcher EC. Blood pressure response to chronic episodic hypoxia: role of the sympathetic nervous system. J Appl Physiol 1997; 83: 95-101.

274 Blake GJ, Ridker PM. C-reactive protein and other inflammatory risk markers in acute coronary syndromes. J Am Coll Cardiol 2003; 41: 37-42.

275 Ridker PM, Hennekens CH, Buring JE, Rifai N. C-reactive protein and other markers of inflammation in the prediction of cardiovascular disease in women. $N$ Engl J Med 2000; 342: 836-843.

276 Ridker PM, Cushman M, Stampfer MJ, Tracy RP, Hennekens $\mathrm{CH}$. Plasma concentration of C-reactive protein and risk of developing peripheral vascular disease. Circulation 1998; 97: 425-428.

277 Shamsuzzaman AS, Winnicki M, Lanfranchi $\mathrm{P}$, et al. Elevated C-reactive protein in patients with obstructive sleep apnea. Circulation 2002; 105: 2462-2464.

278 Yokoe T, Minoguchi K, Matsuo H, et al. Elevated levels of C-reactive protein and interleukin-6 in patients with obstructive sleep apnea syndrome are decreased by nasal continuous positive airway pressure. Circulation 2003; 107: 1129-1134.

279 Tauman R, Ivanenko A, O’Brien LM, Gozal D. Plasma Creactive protein levels among children with sleepdisordered breathing. Pediatrics 2004; 113: e564-e569.

280 Carpagnano GE, Kharitonov SA, Resta O, FoschinoBarbaro MP, Gramiccioni E, Barnes PJ. Increased 8isoprostane and interleukin- 6 in breath condensate of 
obstructive sleep apnea patients. Chest 2002; 122: 1162-1167.

281 Guilleminault C, Kirisoglu C, Ohayon MM. C-reactive protein and sleep-disordered breathing. Sleep 2004; 27: 1507-1511.

282 Athanasios G, Kaditis AG, Alexopoulos EI, et al. Morning levels of C-reactive protein in children with obstructive sleep-disordered breathing. Am J Respir Crit Care Med 2005; 171: 282-286.

283 Ghosh S, May MJ, Kopp EB. NF-kappa B and Rel proteins: evolutionarily conserved mediators of immune responses. Annu Rev Immunol 1998; 16: 225-260.

284 Ross R. Atherosclerosis--an inflammatory disease. N Engl J Med 1999; 340: 115-126.

285 Ridker PM, Rifai N, Pfeffer M, et al. Elevation of tumor necrosis factor-alpha and increased risk of recurrent coronary events after myocardial infarction. Circulation 2000; 101: 2149-2153.

286 Minoguchi K, Tazaki T, Yokoe T, et al. Elevated production of tumor necrosis factor-alpha by monocytes in patients with obstructive sleep apnea syndrome. Chest 2004; 126: 1473-1479.

287 Ryan S, Taylor CT, McNicholas WT. Selective activation of inflammatory pathways by intermittent hypoxia in obstructive sleep apnea syndrome. Circulation 2005; 112: 2660-2667.

288 Ciftci TU, Kokturk O, Bukan N, Bilgihan A. The relationship between serum cytokine levels with obesity and obstructive sleep apnea syndrome. Cytokine 2004; 28: 87-91.

289 Riha RL, Brander P, Vennelle M, et al. Tumour necrosis factor- $\alpha(-308)$ gene polymorphism in obstructive sleep apnoea-hypopnoea syndrome. Eur Respir J 2005; 26: 673-678.

290 Lavie L. Obstructive sleep apnoea syndrome--an oxidative stress disorder. Sleep Med Rev 2003; 7: 35-51.

291 Goldbart A, Row BW, Kheirandish L, et al. Intermittent hypoxic exposure during light phase induces changes in cAMP response element binding protein activity in the rat CA1 hippocampal region: water maze performance correlates. Neuroscience 2003; 122: 585-590.

292 Ohga E, Tomita T, Wada H, Yamamoto H, Nagase T, Ouchi Y. Increased levels of circulating ICAM-1, VCAM1 , and L-selectin in obstructive sleep apnea syndrome. $J$ Appl Physiol 1999; 87: 10-14.

293 Dyugovskaya L, Lavie P, Lavie L. Phenotypic and functional characterization of blood gammadelta $\mathrm{T}$ cells in sleep apnea. Am J Respir Crit Care Med 2003; 168: 242-249.

294 Pober JS. Effects of tumour necrosis factor and related cytokines on vascular endothelial cells. Ciba Found Symp 1987; 131: 170-184.

295 Kritchevsky SB, Cesari M, Pahor M. Inflammatory markers and cardiovascular health in older adults. Cardiovasc Res 2005; 66: 265-275.

296 Lavie L, Kraiczi H, Hefetz A, et al. Plasma vascular endothelial growth factor in sleep apnea syndrome: effects of nasal continuous positive air pressure treatment. Am J Respir Crit Care Med 2002; 165: 1624-1628.

297 Schulz R, Mahmoudi S, Hattar K, et al. Enhanced release of superoxide from polymorphonuclear neutrophils in obstructive sleep apnea. Am J Respir Crit Care Med 2000; 162: 566-570.

298 Dyugovskaya L, Lavie P, Lavie L. Increased adhesion molecules expression and oroduction of reactive oxygen species in leukocytes of sleep apnea patients. Am J Respir Crit Care Med 2002; 165: 934-939.

299 Chen L, Einbinder E, Zhang Q, Hasday J, Balke CW, Scharf SM. Oxidative stress and left ventricular function with chronic intermittent hypoxia in rats. Am J Respir Crit Care Med 2005; 172: 915-920.

$300 \mathrm{Xu} \mathrm{W}$, Chi L, Row BW, et al. Increased oxidative stress is associated with chronic intermittent hypoxia-mediated brain cortical neuronal cell apoptosis in a mouse model of sleep apnea. Neuroscience 2004; 126: 313-323.

301 Veasey SC, Davis CW, Fenik P, et al. Long-term intermittent hypoxia in mice: protracted hypersomnolence with oxidative injury to sleep-wake brain regions. Sleep 2004; 27: 194-201.

302 Zhan G, Serrano F, Fenik P, et al. NADPH oxidase mediates hypersomnolence and brain oxidative injury in a murine model of sleep apnea. Am J Respir Crit Care Med 2005; 172: 921-929.

303 Lavie L, Vishnevsky A, Lavie P. Evidence for lipid peroxidation in obstructive sleep apnea. Sleep 2004; 27: 123-128.

304 Carpagnano GE, Kharitonov SA, Resta O, et al. 8Isoprostane, a marker of oxidative stress, is increased in exhaled breath condensate of patients with obstructive sleep apnea after night and is reduced by continuous positive airway pressure therapy. Chest 2003; 124: 1386-1392.

305 Zhan G, Fenik P, Pratico D, Veasey SC. Inducible nitric oxide synthase in long-term intermittent hypoxia: hypersomnolence and brain injury. Am J Respir Crit Care Med 2005; 171: 1414-1420.

306 Veasey SC, Zhan G, Fenik P, Pratico D. Long-term intermittent hypoxia: reduced excitatory hypoglossal nerve output. Am J Respir Crit Care Med 2004; 170: 665-672.

307 Vogel RA. Heads and hearts: the endothelial connection. Circulation 2003; 107: 2766-2768.

308 Drager LF, Bortolotto LA, Lorenzi MC, Figueiredo AC, Krieger EM, Lorenzi-Filho G. Early signs of atherosclerosis in obstructive sleep apnea. Am J Respir Crit Care Med 2005; 172: 613-518.

309 Kraiczi H, Hedner J, Peker Y, Carlson J. Increased vasoconstrictor sensitivity in obstructive sleep apnea. J Appl Physiol 2000; 89: 493-498.

310 Kato M, Roberts-Thomson P, Phillips BG, et al. Impairment of endothelium-dependent vasodilation of resistance vessels in patients with obstructive sleep apnea. Circulation 2000; 102: 2607-2610.

311 Ip MS, Tse HF, Lam B, Tsang KW, Lam WK. Endothelial function in obstructive sleep apnea and response to treatment. Am J Respir Crit Care Med 2004; 169: 348-353.

312 Carlson JT, Rangemark C, Hedner JA. Attenuated endothelium-dependent vascular relaxation in patients with sleep apnoea. J Hypertens 1996; 14: 77-84.

313 Duchna HW, Guilleminault C, Stoohs RA, et al. Vascular reactivity in obstructive sleep apnea syndrome. Am J Respir Crit Care Med 2000; 161: 187-191. 
314 Ohike Y, Kozaki K, Iijima K, et al. Amelioration of vascular endothelial dysfunction in obstructive sleep apnea syndrome by nasal continuous positive airway pressure--possible involvement of nitric oxide and asymmetric NG, NG-dimethylarginine. Circ J 2005; 69: 221-226.

315 Faulx MD, Larkin EK, Hoit BD, Aylor JE, Wright AT, Redline S. Sex influences endothelial function in sleepdisordered breathing. Sleep 2004; 27: 1113-1120.

316 Joyner MJ, Dietz NM. Nitric oxide and vasodilation in human limbs. J Appl Physiol 1997; 83: 1785-1796.

317 Schulz R, Schmidt D, Blum A, et al. Decreased plasma levels of nitric oxide derivatives in obstructive sleep apnoea: response to CPAP therapy. Thorax 2000; 55: 1046-1051.

318 Ip MS, Lam B, Chan LY, et al. Circulating nitric oxide is suppressed in obstructive sleep apnea and is reversed by nasal continuous positive airway pressure. Am J Respir Crit Care Med 2000; 162: 2166-2171.

319 Agusti AG, Barbe F, Togores B. Exhaled nitric oxide in patients with sleep apnea. Sleep 1999; 22: 231-235.

320 Haight JS, Djupesland PG. Nitric oxide (NO) and obstructive sleep apnea (OSA). Sleep Breath 2003; 7: 53-62.

321 Olopade CO, Zakkar M, Swedler WI, Rubinstein I. Exhaled pentane and nitric oxide levels in patients with obstructive sleep apnea. Chest 1997; 111: 1500-1504.

322 Schulz R, Seeger W, Grimminger F. Serum nitrite/nitrate levels in obstructive sleep apnea. Am J Respir Crit Care Med 2001; 164: 1997-1998.

323 Phillips BG, Narkiewicz K, Pesek CA, Haynes WG, Dyken ME, Somers VK. Effects of obstructive sleep apnea on endothelin-1 and blood pressure. J Hypertens 1999; 17: 61-66.

324 Grimpen F, Kanne P, Schulz E, Hagenah G, Hasenfuss G, Andreas S. Endothelin-1 plasma levels are not elevated in patients with obstructive sleep apnoea. Eur Respir J 2000; 15: 320-325.

325 Nieto FJ, Herrington DM, Redline S, Benjamin EJ, Robbins JA. Sleep apnea and markers of vascular endothelial function in a large community sample of older adults. Am J Respir Crit Care Med 2004; 169: 354-360.

326 von Kanel R, Dimsdale JE. Hemostatic alterations in patients with obstructive sleep apnea and the implications for cardiovascular disease. Chest 2003; 124: 1956-1967.

327 Shitrit D, Peled N, Shitrit AB, et al. An association between oxygen desaturation and $\mathrm{D}$-dimer in patients with obstructive sleep apnea syndrome. Thromb Haemost 2005; 94: 544-547.

328 von Kanel R, Loredo JS, Powell FL, Adler KA, Dimsdale JE. Short-term isocapnic hypoxia and coagulation activation in patients with sleep apnea. Clin Hemorheol Microcirc 2005; 33: 369-377.

329 Steiner S, Jax T, Evers S, Hennersdorf M, Schwalen A, Strauer BE. Altered blood rheology in obstructive sleep apnea as a mediator of cardiovascular risk. Cardiology 2005; 104: 92-96.

330 Kaditis AG, Alexopoulos EI, Kalampouka E, et al. Morning levels of fibrinogen in children with sleepdisordered breathing. Eur Respir J 2004; 24: 790-797.

331 Shimizu M, Kamio K, Haida M, et al. Platelet activation in patients with obstructive sleep apnea syndrome and effects of nasal-continuous positive airway pressure. Tokai J Exp Clin Med 2002; 27: 107-112.

332 Hui DS, Ko FW, Fok JP, et al. The effects of nasal continuous positive airway pressure on platelet activation in obstructive sleep apnea syndrome. Chest 2004; 125: 1768-1775.

333 Strohl KP, Novak RD, Singer W, et al. Insulin levels, blood pressure and sleep apnea. Sleep 1994; 17: 614-618.

334 Vgontzas AN, Papanicolaou DA, Bixler EO, et al. Sleep apnea and daytime sleepiness and fatigue: relation to visceral obesity, insulin resistance, and hypercytokinemia. J Clin Endocrinol Metab 2000; 85: 1151-1158.

335 Tan KC, Chow WS, Lam JC, et al. Advanced glycation endproducts in nondiabetic patients with obstructive sleep apnea. Sleep 2006; 29: 329-333.

336 Polotsky VY, Li J, Punjabi NM, et al. Intermittent hypoxia increases insulin resistance in genetically obese mice. $J$ Physiol 2003; 552: 253-264.

337 Soderberg S, Ahren B, Jansson JH, et al. Leptin is associated with increased risk of myocardial infarction. J Intern Med 1999; 246: 409-418.

338 Greenberg AS, Obin MS. Obesity and the role of adipose tissue in inflammation and metabolism. Am J Clin Nutr 2006; 83: Suppl. 2, 461S-465S.

339 O'Donnell CP, Tankersley CG, Polotsky VP, Schwartz AR, Smith PL. Leptin, obesity, and respiratory function. Respir Physiol 2000; 119: 163-170.

340 Ambrosini G, Nath AK, Sierra-Honigmann MR, FloresRiveros J. Transcriptional activation of the human leptin gene in response to hypoxia. J Biol Chem 2002; 277: 34601-34609.

341 Shimura R, Tatsumi K, Nakamura A, et al. Fat accumulation, leptin, and hypercapnia in obstructive sleep apneahypopnea syndrome. Chest 2005; 127: 543-549.

342 Phipps PR, Starritt E, Caterson I, Grunstein RR. Association of serum leptin with hypoventilation in human obesity. Thorax 2002; 57: 75-76.

343 Barcelo A, Barbe F, Llompart E, et al. Neuropeptide Y and leptin in patients with obstructive sleep apnea syndrome: role of obesity. Am J Respir Crit Care Med 2005; 171: 183-187.

344 Tatsumi K, Kasahara Y, Kurosu K, Tanabe N, Takiguchi Y, Kuriyama T. Sleep oxygen desaturation and circulating leptin in obstructive sleep apnea-hypopnea syndrome. Chest 2005; 127: 716-721.

345 Patel SR, Palmer LJ, Larkin EK, Jenny NS, White DP, Redline S. Relationship between obstructive sleep apnea and diurnal leptin rhythms. Sleep 2004; 27: 235-239.

346 Sanner BM, Kollhosser P, Buechner N, Zidek W, Tepel M. Influence of treatment on leptin levels in patients with obstructive sleep apnoea. Eur Respir J 2004; 23: 601-604.

347 Harsch IA, Konturek PC, Koebnick C, et al. Leptin and ghrelin levels in patients with obstructive sleep apnoea: effect of CPAP treatment. Eur Respir J 2003; 22: 251-257.

348 Shimizu K, Chin K, Nakamura T, et al. Plasma leptin levels and cardiac sympathetic function in patients with obstructive sleep apnoea-hypopnoea syndrome. Thorax 2002; 57: 429-434. 
349 Schafer H, Pauleit D, Sudhop T, Gouni-Berthold I, Ewig S, Berthold HK. Body fat distribution, serum leptin, and cardiovascular risk factors in men with obstructive sleep apnea. Chest 2002; 122: 829-839.

350 Ip MS, Lam KS, Ho C, Tsang KW, Lam W. Serum leptin and vascular risk factors in obstructive sleep apnea. Chest 2000; 118: 580-586.

351 Weiss R, Dziura J, Burgert TS, et al. Obesity and the metabolic syndrome in children and adolescents. $N$ Engl J Med 2004; 350: 2362-2374.

352 Pontiroli AE. Type 2 diabetes mellitus is becoming the most common type of diabetes in school children. Acta Diabetol 2004; 41: 85-90.

353 Ancoli-Israel S, DuHamel ER, Stepnowsky C, Engler R, Cohen-Zion $\mathrm{M}$, Marler $\mathrm{M}$. The relationship between congestive heart failure, sleep apnea, and mortality in older men. Chest 2003; 124: 1400-1405.

354 Lavie L, Lavie P. Ischemic preconditioning as a possible explanation for the age decline relative mortality in sleep apnea. Med Hypotheses 2006; 66: 1069-1073.

355 Kapsimalis F, Kryger MH. Gender and obstructive sleep apnea syndrome, part 2: mechanisms. Sleep 2002; 25: 499-506.

356 Edwards N, Wilcox I, Sullivan CE. Sleep apnea in women. Thorax 1998; 53: Suppl. 3, S12-S15.

357 Jordan AS, Wellman A, Edwards JK, et al. Respiratory control stability and upper airway collapsibility in men and women with obstructive sleep apnea. J Appl Physiol 2005; 99: 2020-2027.
358 Iczi B, Vennelle M, Liston WA, Dundas KC, Calder AA, Douglas NJ. Sleep disordered breathing and upper airway size in pregnancy and post-partum. Eur Respir J 2006; 27: 321-327.

359 Connolly G, Razak A, Hayanga A, Russell A, McKenna P, McNicholas WT. Inspiratory flow limitation during sleep in pre-eclampsia: comparison with normal pregnant and nonpregnant women. Eur Respir J 2001; 18: 672-676.

360 Edwards N, Blyton DM, Kirjavainen TT, Sullivan CE. Hemodynamic responses to obstructive respiratory events during sleep are augmented in women with preeclampsia. Am J Hypertens 2001; 14: 1090-1095.

361 Yinon D, Lowenstein L, Suraya S, et al. Pre-eclampsia is associated with sleep-disordered breathing and endothelial dysfunction. Eur Respir J 2006; 27: 328-333.

362 Young T, Finn L, Austin D, Peterson A. Menopausal status and sleep-disordered breathing in the Wisconsin Sleep Cohort Study. Am J Respir Crit Care Med 2003; 167: 1181-1185.

363 Shahar E, Redline S, Young T, et al. Hormone replacement therapy and sleep-disordered breathing. Am J Respir Crit Care Med 2003; 167: 1186-1192.

364 Young T, Finn L. Epidemiological insights into the public health burden of sleep disordered breathing: sex differences in survival among sleep clinic patients. Thorax 1998; 53: Suppl 3., S16-S19.

365 Patel SR. Shared genetic risk factors for obstructive sleep apnea and obesity. J Appl Physiol 2005; 99: 1600-1606. 